The Texas Medical Center Library

DigitalCommons@TMC

The University of Texas MD Anderson Cancer Center UTHealth Graduate School of

Biomedical Sciences Dissertations and Theses

(Open Access)
The University of Texas MD Anderson Cancer

Center UTHealth Graduate School of

Biomedical Sciences

\title{
First Trimester Screening and its Impact on Uptake of Diagnostic Testing
}

Deanna Darnes

Follow this and additional works at: https://digitalcommons.library.tmc.edu/utgsbs_dissertations

Part of the Obstetrics and Gynecology Commons

\section{Recommended Citation}

Darnes, Deanna, "First Trimester Screening and its Impact on Uptake of Diagnostic Testing" (2010). The University of Texas MD Anderson Cancer Center UTHealth Graduate School of Biomedical Sciences Dissertations and Theses (Open Access). 52.

https://digitalcommons.library.tmc.edu/utgsbs_dissertations/52

This Thesis (MS) is brought to you for free and open access by the The University of Texas MD Anderson Cancer Center UTHealth Graduate School of Biomedical Sciences at DigitalCommons@TMC. It has been accepted for inclusion in The University of Texas MD Anderson Cancer Center UTHealth Graduate School of Biomedical Sciences Dissertations and Theses (Open Access) by an authorized administrator of DigitalCommons@TMC. For more information, please contact digitalcommons@library.tmc.edu.

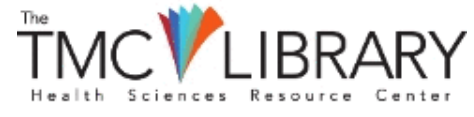




\section{Background}

\section{Introduction:}

From 1990 to 2005, the pregnancy rate has increased among women age 35 and older. Based on the National Vital Statistics Reports (NVSR), in October 2009 the pregnancy rate of women who are 35 to 44 years old has increased from 68.3 to 94.8 per 1,000 women, which equates to a 38.8\% increase (Abma JC, Henshaw SK, Mosher WD, Ventura SJ, 2009). In addition to her routine prenatal care, a woman who is age 35 and older may be referred to a genetic counselor. The primary reason a patient is referred for prenatal genetic counseling is maternal age and the associated increased risk for fetal aneuploidy (Berkowitz RL, Roberts J, Minkoff H, 2006). Women who are 35 years or older at the time of delivery, an age referred to as advanced maternal age (AMA), are commonly referred to a prenatal genetic counselor because this (Berkowitz RL et al, 2006; Kirz DS et al, 1985). In addition to genetic counseling, AMA women are often offered biochemical screening and diagnostic testing to determine their individual risk for fetal aneuploidy (Berkowitz RL et al, 2006). Support for the age of 35 as the referral age for genetic counseling diagnostic testing is based on data from studies in the 1970s showing that the rate of miscarriage following a prenatal diagnostic procedure is equal to that of fetal aneuploidy (Berkowitz RL et al, 2006; Hook et al, 1981). With the rate of pregnancies in this age group increasing, even more patients would be referred for prenatal genetic counseling based on their age alone.

The practice of only offering genetic counseling and diagnostic testing to AMA women is changing. In January 2007, the American College of Obstetricians and Gynecologists (ACOG) released a statement recommending that genetic screening, 
including first trimester screening (FTS), should be offered to all pregnant women regardless of their age (ACOG 2007a). With this guideline in place, physicians are now encouraged to offer FTS as an option to AMA women, in addition to diagnostic testing and genetic counseling (ACOG 2007a). While diagnostic testing represents the definitive assessment of fetal aneuploidy, it poses a risk to the pregnancy. In contrast, FTS does not provide a definitive assessment for fetal aneuploidy; however, it does not pose a risk to the pregnancy (ACOG 2007a; ACOG 2007b). Therefore, some AMA women may prefer FTS before deciding whether or not to proceed with diagnostic testing.

During a genetic counseling session, AMA women are informed of the risk for fetal aneuploidy and ways of appreciating their individual risk (Berkowitz, RL et al. 2006; ACOG 2007a). In the past, in order to evaluate the risk for fetal aneuploidy, AMA women were typically offered second trimester biochemical screening and/or prenatal diagnostic testing (PDT) (ACOG, 2007a; ACOG, 2007b). The different screening options available today utilize many components which include free or total beta human chorionic gonadotropin ( $\beta$ hCG), nuchal translucency (NT) and pregnancy-associated plasma protein A (PAPP-A) during the $1^{\text {st }}$ trimester and maternal serum alpha-fetoprotein (MSAFP), human chorionic gonadotropin (hCG), unconjugated estriol, and inhibin A during the $2^{\text {nd }}$ trimester (ACOG 2007a). The different screening options use various combinations of these components, and each option can only be performed within a particular gestational age window. The current version of FTS (NT, free $\beta$-hCG, PAPP-A) can be performed in the first trimester. It can be utilized for trisomy 21 and trisomy 18 risk assessment (ACOG, 2007a). A Quadruple screen, which uses a combination of MSAFP, hCG, unconjugated estriol, and inhibin A can be performed in the second trimester (ACOG, 2007a; Breathnach FM, Malone FD, Lambert- 
Messerlian G, Cuckle HS, Porter TF, Nyberg DA et al, 2007). It can be used to screen for trisomy 21 and trisomy 18 as well (ACOG, 2007a). Currently, in our referral clinics it appears that FTS and Quadruple screen are the most common screening techniques requested. Other options that are available to screen for fetal aneuploidy include screening protocols that implement a combination of the $1^{\text {st }}$ and $2^{\text {nd }}$ trimester methodology to give an overall risk assessment (ACOG, 2007a). Examples include: integrated, sequential, and contingency screening.

The diagnostic testing that is typically offered to AMA women consists of chorionic villus sampling $(\mathrm{CVS})$ in the $1^{\text {st }}$ trimester or amniocentesis in the $2^{\text {nd }}$ trimester $(A C O G$, 2007a; ACOG, 2007b). One consequence of participating in screening options that include both $1^{\text {st }}$ and $2^{\text {nd }}$ trimester analytes is that the option of CVS is no longer available (ACOG, 2007a). FTS currently consists of maternal age, NT, and the measurement of two maternal analytes: free $\beta$-hCG and PAPP-A (Dugoff L, Hobbins JC, Malone FD, Porter TF, Luthy D, Comstock $\mathrm{CH}$ et al, 2004). FTS has a detection rate of $80-85 \%$ for trisomy 21 and a 90-95\% rate for trisomy 18 (Malone FD et al, 2005; Kagan KO et al, 2008a; Kagan KO et al, 2008b). In spite of such a good detection rate, FTS remains a screening and not a diagnostic test. A recent study has shown that there has been a decline in the request for CVS and amniocentesis among AMA patients (Henry GP, Britt DW, Evans MI., 2008). A strong influence on this trend may have been the accuracy and availability of FTS.

By comparing the two years prior and the two years after the January 2007 ACOG statement, our study will determine if the uptake of PDT has changed in our clinics. We will also seek to understand how positive and negative FTS results affect a woman's decision to have PDT, and discover the possible reasons why AMA women may prefer FTS. 


\section{First Trimester Screening}

The practice of screening women in the first trimester for fetal aneuploidy has been evolving over the past 20 years. Currently FTS may be considered combined screening due to its inclusion of maternal analytes and ultrasound markers (Werner EF, Pastore LM, Karns LB, Ventura KA, Saller DN., 2008). In the early 1990s, FTS only included maternal age and NT, which is the ultrasound measurement of the fluid that collects behind the fetal neck (Nicolaides KH, Azar G, Byrne D, Mansur C, Marks K., 1992). An ultrasound NT measurement of $\geq 3 \mathrm{~mm}$ is considered abnormal (Nicolaides KH et al, 1992). NT results are the most informative when measured between 10 and 14 weeks (Nicolaides KH et al, 1992). As the NT increases, the risk for fetal aneuploidy also increases (Nicolaides KH et al, 1992).

Subsequent studies have sought to determine how maternal analytes could be used to further the risk assessment for fetal aneuploidy. In the early 1990s the maternal analyte PAPP-A was studied to determine its usefulness as a screening tool. These studies wanted to understand if there was a correlation between the amount of PAPP-A in maternal blood and fetal aneuploidy or demise (Hurley PA, Ward RH, Teisner B, Iles RK, Lucas M, Grudzinskas JG., 1993). Hurley et al. demonstrated that a decreased level of PAPP-A was associated with trisomy 21 and that these low levels could be detected as early as the first trimester. From these results, they concluded that using a cut off of 0.3 multiples of the median for PAPP-A, pregnancies at an increased risk for trisomy 21 could be identified (Hurley PA et al, 1993). Use of PAPP-A in conjunction with maternal age was also studied as a first trimester screening technique for trisomy 21 (Brambati B, Macintosh MC, Teisner B, Maguiness S, Schrimanker K, Lanzani A et al, 1993). By using PAPP-A alone, 58\% of 
trisomy 21 fetuses could be detected, whereas PAPP-A paired with maternal age would detect $62 \%$ of trisomy 21 fetuses (Brambati B. et al, 1993).

To increase the detection rate of trisomy 21 in the first trimester, the maternal analyte free $\beta$-hCG was looked at as a possible addition to the first trimester screening protocol. Previous studies have found that free $\beta$-hCG was increased in pregnancies affected with trisomy 21 (Noble PL, Abraha HD, Snijders RJ, Sherwood R, Nicolaides KH., 1995). To validate this observation, Nobles et al. compared free $\beta$-hCG levels in fetuses affected with trisomy 21 to that of fetuses without trisomy 21 . The mean level for free $\beta$-hCG in trisomy 21 affected fetuses was 1.13 times higher than that of fetuses without trisomy 21 (Noble PL, Abraha HD, Snijders RJ, Sherwood R, Nicolaides KH., 1995). Combining free $\beta$-hCG, NT, and maternal age yielded a detection rate of $85 \%$ with a false positive rate of $5 \%$ for trisomy 21 (Noble PL et al, 1995).

In 1997 the combination of PAPP-A, free $\beta$-hCG, NT, and maternal age to detect trisomy 21 in the first trimester was first evaluated (Orlandi F, Damiani G, Hallahan TW, Krantz DA, Macri JN., 1997). This study included 2010 pregnant women between 9 weeks and 13 weeks 4 days gestation. The combination of PAPP-A, $\beta$-hCG, NT, and maternal age resulted in an $87 \%$ detection rate for trisomy 21 (Orlandi $\mathrm{F}$ et al, 1997).

Following the Orlandi et al. study, more studies have evaluated the combination of PAPP-A, free $\beta$-hCG, NT, and maternal age in the detection of fetal aneuploidy. Initial studies using these variables focused on the detection of trisomy 21. As research improved, additional studies sought to determine if these variables could be used to detect whether or not pregnancies were at an increased risk for conditions other than trisomy 21. In 1994 Brizote et al. used PAPP-A, NT, and maternal age as a way to detect trisomy 18. Trisomy 
18 could be detected at a rate of $89 \%$ with $5 \%$ false positive rate (Brizot ML, Snijders RJ, Bersinger NA, Kuhn P, Nicolaides KH, 1994). Biagiotti et al. in 1998 suggested that decreased levels of both PAPP-A and free $\beta$-hCG can be identified in pregnancies at an increased risk for trisomy 18 . Low levels of these maternal analytes detected trisomy 18 at a $45.8 \%$ and $32.5 \%$ rate, respectively, with a $5 \%$ false positive rate. When using these two analytes in combination with one another, in addition to maternal age, a $71.6 \%$ detection rate was found with a $2 \%$ false positive rate (Biagiotti R, Cariati E, Brizzi L, Cappelli G, D'Agata A, 1998).

In 1998, Tul et al. evaluated retrospectively 50 pregnancies affected by trisomy 18 and 947 controls. They observed lower levels of PAPP-A and free $\beta$-hCG in addition to an increased NT in the affected pregnancies. The combination of these variables detected $89 \%$ of pregnancies affected with trisomy 18 with a $1 \%$ false positive rate (Tul N, Spencer K, Noble P, Chan C, Nicolaides K., 1999).

The information garnered by all these studies shows that using a combination of maternal age, NT, and the maternal analytes PAPP-A and free $\beta$-hCG has the ability to detect trisomy 21 and trisomy 18 at rates higher than those of traditional second trimester screening options.

\section{$\underline{\text { Advancements in FTS }}$}

As prior research has shown FTS to be an effective screening tool for trisomy 21 and 18, FTS may also be applicable to screening for other chromosome abnormalities. Studies are presently analyzing the utility of including other ultrasound markers as a part of the FTS protocol in an attempt to determine if FTS can detect other chromosome abnormalities, such 
as sex chromosome anomalies or trisomy 13, as well as increase the detection rate of trisomy 21 and trisomy 18.

Fetal sex chromosomes disorders are the most common chromosomal abnormality in liveborns (Spencer K, Tul N, Nicolaides KH., 2000). Now that screening for trisomy 21 and 18 has moved into the first trimester, some have suggested the benefits of using FTS for sex chromosome disorders. Spencer et al. evaluated the detection of sex chromosomal disorders via FTS. They found that in pregnancies affected by Turner syndrome (45, X), NT was significantly larger, PAPP-A was significantly lower, and free $\beta$-hCG was equal to or greater than the controls (Spencer K et al, 2000). According to them, FTS could detect $90 \%$ of fetuses affected by Turner syndrome (Spencer K et al, 2000). Fetuses with other sex chromosome disorders, 47XXX, 47XXY, 47XYY had significantly increased NT but there were no significant differences in maternal analytes (Spencer K et al, 2000).

The third most common autosomal trisomy is trisomy 13 (Spencer K, Ong C, Skentou H, Liao AW, H Nicolaides K., 2000). Research has evaluated whether trisomy 13 could be detected using FTS. Previous studies have shown that trisomy 13 has a pattern that is similar to trisomy 18 with regard to NT and maternal analyte levels (Spencer K et al, 2000). Therefore, it may be possible to detect trisomy 13 using FTS in the same manner trisomy 18 is detected. When compared to fetuses not affected with trisomy 13 , trisomy 13 fetuses had a significantly higher NT and a significantly lower PAPP-A and free $\beta$-hCG (Spencer K et al, 2000). By using FTS to identify this pattern, pregnancies affected with trisomy 13 can be detected at an $84 \%$ rate with a $0.1 \%$ false positive rate.

In 2001, Cicero et al. investigated the possibility of adding fetal nasal bone assessment to the FTS protocol to modify the detection rate of trisomy 21 . By examining 
the fetal profile for the presence or absence of the nasal bone, they found that the nasal bone was absent in 43 of 59 (73\%) fetuses affected with trisomy 21 (Cicero S, Curcio P, Papageorghiou A, Sonek J, Nicolaides K., 2001). Including fetal nasal bone assessment along with NT, maternal age, and maternal analytes, the detection rate of trisomy 21 could be $85 \%$ with a $1 \%$ false positive rate. Further evaluation of the same screening protocol by Cicero et al. in 2003 determined a detection rate of $97 \%$ with a $5 \%$ false positive rate for trisomy 21 (Cicero S, Bindra R, Rembouskos G, Spencer K, Nicolaides KH., 2003). In order to reduce the false positive rate to $0.5 \%$, the achievable detection rate would still be 90.5\% (Cicero S et al, 2003). Although several studies have shown the effectiveness of using fetal nasal bone as an ultrasound marker, fetal nasal bone assessment has not become a standard part of FTS due to the difficultly in interpretation and low specificity (Borrell, 2009). 


\section{Prenatal Diagnostic Testing}

A diagnostic test, rather than a screening test, is required to determine the fetal karyotype. During pregnancy, the two most common diagnostic testing options available are CVS and amniocentesis. In the past, both procedures were primarily offered to AMA women due to the age related risk for fetal aneuploidy being equal to or greater than that of the procedural risk. In December 2007, ACOG set forth new guidelines recommending that diagnostic testing be made available to all women, regardless of age (ACOG, 2007b).

Each diagnostic procedure can only be performed at specific times during the pregnancy. CVS can be performed during the first trimester, specifically between 10 and 14 weeks gestation (ACOG, 2007b). Amniocentesis can be performed during the second trimester, ideally between 16 and 20 weeks gestation (ACOG, 2007b). Complications involved in each procedure include the possibility of fetal loss, rupture of fetal membranes, infection, cramping, and/or bleeding (ACOG, 2007b). The overall accuracy of both procedures is 99\% (ACOG, 2007b; Jackson LG, Zachary JM, Fowler SE, Desnick RJ, Golbus MS, Ledbetter DH, Mahoney MJ, Pergament E, Simpson JL, Black S, et al., 1992). There have been many studies evaluating the risk for fetal loss with each of these procedures. Recent studies have shown that there is as little as a $0.13 \%$ risk for pregnancy loss with amniocentesis and 0.5\% risk for CVS (Odibo AO D. J., 2008; Odibo AO G. D., 2008). Even though screening is not as accurate, there has been an increase in the request for FTS and a decline in the request of diagnostic testing (Henry GP, Britt DW, Evans MI., 2008). Past research has suggested that the availability of screening in the first trimester has caused this decline in PDT (Dommergues M, 2001; Chasen ST, 2004; Mulvey S, 2000; Zoppi MA, 2001). 


\section{The Effect of FTS on Patient Decision Making and Diagnostic Testing Uptake}

A study by Mulvey and Wallace (2000) found that when given the choice of screening in the first trimester by use of NT alone or second trimester marker screening, $74 \%$ of women were more inclined to have a NT performed in the first trimester.

Participants stated they preferred NT screening because it could provide earlier results about multiple conditions (Mulvey S, Wallace EM., 2000).

The availability of screening in the first trimester prompted the consideration of the possible impact it may have on the uptake of diagnostic testing, especially in the AMA population. A few studies have been conducted to evaluate the effect NT and maternal age screening has on a woman's decision to have diagnostic testing (Dommergues M et al, 2001; Chasen ST et al, 2004; Zoppi MA et al, 2001).

In a 2001 study, women who were AMA and screened by NT alone were followed to determine if they subsequently had diagnostic testing (Dommergues M, Audibert F, Benattar C, Champagne C, Gomel V, Frydman R., 2001). They found that of the 229 women with a negative result, only $122(53 \%)$ went on to have PDT. In comparison, 105 women of the $130(81 \%)$ who had a positive result went on to have PDT. This study showed that women with a negative NT result, (below $3 \mathrm{~mm}$ ) were less likely to have an amniocentesis (Dommergues M et al., 2001). Further analysis of this trend was achieved by comparing pre-NT (1995) and post-NT (1999) populations (Zoppi MA, Ibba RM, Putzolu M, Floris M, Monni G., 2001). Women who were offered screening by NT alone (1999 group) were found to decline diagnostic testing more often than women who did not have NT screening available to them (1995 group) - 30\% declined diagnostic testing in 1999 vs. $22 \%$ in 1995 
(Zoppi MA et al, 2001). Further evidence to support the finding that NT screening availability impacts diagnostic testing uptake was presented by Chasen et al. in 2004. AMA women were offered screening by NT alone. The rate of CVS decreased from $5.2 \%$ to $2.7 \%$, while the rate of amniocentesis decreased from $62.5 \%$ to $57.3 \%$ in women ages $35-39$. These values represented an overall significant decline in the rate of diagnostic testing among women in this age group (Chasen ST, McCullough LB, Chervenak FA., 2004).

While the above studies looked at how the use of NT and maternal age affected uptake of diagnostic testing, one study looked at FTS in its current form (NT, maternal age, and maternal analytes) (Wray AM, Ghidini A, Alvis C, Hodor J, Landy HJ, Poggi SH., 2005). At Georgetown University Hospital, the rate of AMA women receiving genetic counseling before 13 weeks gestation and diagnostic testing was compared before and after FTS became available (2001 vs. 2003). According to this study, in 2003 more patients came in for genetic counseling but fewer diagnostic tests were ordered. Only $19 \%$ of patients requested diagnostic testing after FTS was offered to them in 2003, while $68 \%$ of patients requested diagnostic testing in 2001 (Wray AM et al, 2005). It was also reported that patients weighed the accuracy and early availability of FTS when considering diagnostic testing.

\section{$\underline{\text { Specific Aims/Significance }}$}

Though FTS in its current form has been offered to patients on a more regular basis since January 2007, only one study to our knowledge has looked at this screening option's impact on the uptake of diagnostic testing. With the availability of FTS and the increased public awareness of this screening option, it seems as though patients are electing to undergo FTS rather than wait until the second trimester to pursue screening and/or diagnostic testing 
options. Our study aims to determine if the uptake of PDT has changed since the January 2007 ACOG statement in our clinics, how positive or negative FTS results may affect a woman's decision to have PDT, and what the patient's intentions are on how they will use their FTS results. Our study will seek to complement previous studies by discovering other possible reasons why patients decline or accept diagnostic testing after having FTS. We will also evaluate patients' knowledge and understanding of FTS by discovering how the option of FTS was initially presented to them and determine how this factor may influence their decision to have FTS.

Our results will serve to give genetic counselors and other health care professionals insight into the patient's decision making process as it pertains to FTS and PDT.

\section{Material and Methods}

\section{$\underline{\text { Study Design }}$}

The aim of this study was to determine if there was a significant change in the uptake of PDT in the two years prior compared to the two years after the January 2007 ACOG statement. In conjunction with this primary aim, we sought to determine the possible reasons why women decline or accept PDT. A review of our general prenatal database, which contains all women having genetic counseling, as well as a review of a first trimester screen database, which includes women who pursue first trimester screening, was performed covering the years 2005-2009. We reviewed these databases to determine the number of AMA women seen for genetic counseling, the number of CVS and amniocentesis procedures performed on AMA women after FTS, and the number of positive and negative FTS results. Eligibility for FTS was based on patient intake between 11 and 13 weeks 6 days gestation. Those women who were eligible for FTS and AMA were given two surveys: 
one prior to their genetic counseling appointment and one after. The pre-counseling survey was used to determine the patient's knowledge of FTS and their intentions relative to PDT. The post-counseling survey was used to determine what the patient had learned about FTS, their reasoning for having FTS, how the FTS results would be used in the decision regarding PDT, and if the patient will accept or decline PDT.

A second review of the prenatal database covered the time period of the survey disbursement (September 2009 - March 2010). The purpose of this review was to determine if the uptake rates accurately reflected the patient intentions as stated in the surveys, as well as to determine if there was a significant difference in PDT uptake during 2009 -2010 compared to the 2007-2009 time period. We also reviewed the amount of positive and negative FTS results and correlated the number of positive/negative results and number of PDT performed during this time period. Only aggregate data was compared.

A survey was given to 50 obstetricians who had referred at least four patients to our clinics. The purpose of this survey was to identify what information the referring physicians give to their patients pertaining to FTS, what patients are referred for FTS, and how they feel FTS impacts the patient.

Survey distribution began on September $23^{\text {rd }} 2009$ at the University of Texas Professional Building (UTPB). This was followed by distribution beginning on October $12^{\text {th }}$ and October $23^{\text {rd }} 2009$ at Memorial Hermann Memorial City Hospital (MHMC) and Memorial Hermann Southwest Hospital (MHSW), respectively.

We hypothesized that since the January 2007 ACOG statement there has been a decrease in the uptake of PDT. 


\section{$\underline{\text { Inclusion and Exclusion Criteria }}$}

In order to be eligible for the survey portion of our study, participants had to be 35 or more years old at the time of delivery and eligible for FTS. Eligibility for FTS was based on if the participant sought genetic counseling between 11 and 13 weeks 6 days. Women were excluded from participation of the survey portion of the study if they would not be 35 at time of delivery, if they did not have genetic counseling during the stipulated time period, and if they needed a translator during their session.

In order for a patient to be included in the database review, the patients had to be seen at UT associated clinics by a genetic counselor. Within the database, each patient's date of birth, gestation, and expected date of delivery were recorded. Patients with incomplete information were not included in the review. Patients who were 35 or older at time of delivery were grouped by time periods: 2005-2007, 2007-2009, and September 2009 to March 2010. Within the 2007 to 2009 time period and September 2009 to March 2010 period, two subgroups were created: women seen $<14$ weeks and those seen $\geq 14$ weeks (i.e., ineligible for FTS). Within the database there is a field for amniocentesis and CVS. If this field is selected, it denotes that the patient had either an amniocentesis or a CVS performed. The amount of PDT procedures performed was able to be counted in this manner. Patients seen during the September 2009 to March 2010 were included if they were AMA. These patients were also split into the same two gestational age categories. The number of PDT procedures for each gestation period was determined. 


\section{Database}

There are a total of seven UT associated prenatal clinics. Surveys were administered at only three clinics: UTPB, MHMC, and MHSW, but all seven clinics were used to determine the overall rate of screening and prenatal diagnostic procedures performed. Patient's demographic and medical information data were entered into a Microsoft Access database by genetic counselors.

\section{Study Approval}

The Committee for the Protection of Human Subjects of the University of Texas Houston Health Science Center approved this study on September $19^{\text {th }} 2009$ (CPHS HSCMS-09-0396).

\section{$\underline{\text { Sample Size }}$}

We anticipated that 250 AMA women would be eligible for FTS during each study period based on the average number of AMA/FTS patients seen in one month. This number was then multiplied by three to reflect our proposed distribution time. This was the maximum number allotted for this study, though there were no time limits or constraints for when this sample size could be achieved.

\section{$\underline{\text { Surveys }}$}

Each survey was developed by the PI and was approved prior to IRB submission by the thesis committee. The surveys contained multiple choice questions and a ranking question. Each survey was designed to take no more than 10-15 minutes for each participant to complete. Participants were instructed to answer each question to the best of their ability and they had the option of skipping questions. Patients also had the option to choose more 
than one response. Each answer was numerically coded and entered into an Excel spreadsheet database.

In addition to the questions regarding FTS and PDT, demographic information including age, ethnicity, education, income, past experiences with PDT, pregnancy history, and personal experiences with genetic syndromes were included. A complete version of the pre- and post-counseling surveys can be found within the appendix.

\section{$\underline{\text { Survey Collection }}$}

Participants were selected from our referral patient base depending on the indication for genetic counseling. They were given the pre-counseling survey and an information sheet describing the study along with their routine paper work prior to the genetic counseling appointment. The post-genetic counseling survey was given to the patients by their genetic counselor. The survey was completed while the patients waited for their ultrasound appointment. Survey collection began September $23^{\text {rd }} 2009$ at UTPB and ended on March $5^{\text {th }}$ 2010. Survey collection began on October $12^{\text {th }} 2009$ at MHMC and ended on March $3^{\text {rd }}$ 2010. Survey collection began on October $23^{\text {rd }} 2009$ at MHSW and ended February $26^{\text {th }}$ 2010.

The referring obstetrician surveys and accompanying information sheets on the study were distributed either in person (15) or by mail (35). The completed surveys were returned in a sealed envelope. Obstetrician surveys were distributed in December 2009 and January 2010. Surveys were included in the study if received by March $5^{\text {th }} 2010$. 


\section{Statistical Analysis}

Chi-square analysis was performed to compare the uptake of PDT procedures between time periods of 2005-2007 and 2007-2009 as well as to identify changes in the patient's intentions regarding PDT. Possible confounding factors related to the patient's intentions regarding PDT prior to and after genetic counseling were also considered. The data obtained from the surveys was largely descriptive.

A Wilcoxon signed rank test was performed to determine if there was a difference in the patient's plan regarding PDT prior to and after completing genetic counseling and what type of difference (positive, negative, or neutral) was observed. This test was also performed when controlling for each possible confounding variable (age, number of pregnancies, education, household income, number of living children, and ethnicity) in the decision regarding PDT pre-counseling and post-counseling.

The statistical analysis was performed using the statistical software program STATA. Frequency distribution analysis was used to determine the number of participants who selected each choice from each of the survey questions. Summary statistics were performed on the post genetic counseling survey to determine both the top choices selected and the average rank of each choice. Frequency distribution analysis was performed on the referring physician surveys.

\section{Survey Data Interpretation}

The patient surveys were separated into three categories: exclusive completion of the pre-counseling survey, exclusive completion of the post-counseling survey, and completion 
of both surveys. Frequency distribution analysis was performed for each category. Data from participants who completed both surveys permitted an assessment of the learning process relative to FTS, consequent planning regarding PDT, and how the planning regarding PDT may have changed after the genetic counseling session.

For the merged analysis the demographic data were categorized as follows: Age $(<38$ and $\geq 38$ ), Number of pregnancies (null parity, one, two, three plus), Education (high school, college, graduate school), Annual household income (\$0-50,000, \$50,001-100,000, $\$>100,000$ ), Number of living children (zero, one, two, and three), and Ethnicity (Caucasian, African-American, Hispanic, and Asian).

To obtain an accurate interpretation of those patients who were considering PDT pre-counseling, we did not include those participants who were unaware of FTS and/or PDT, those who chose the option "other", or those who did not answer this question. However, we did include their responses for other questions. Similarly, from the post-counseling surveys, we excluded those participants who, for the question pertaining to their intention to have PDT now that they've learned about FTS, answered “other”, did not answer, or did not understand FTS and/or PDT.

The last question on the survey pertained to how the plan regarding PDT may have changed after the genetic counseling session. For this question we only included in analysis those participants who answered either "yes" or" no", or stated anything to the effect of "I will decide after I receive my results". For this particular question we regarded statements such as "I did not have a plan, I will decide after I receive my results" as "undecided".

\section{Results}




\section{$\underline{\text { Sample Size }}$}

The prenatal genetic

counseling database review

for the 2005-2007 time

period for all UT associated

clinics elicited the following:

4,040 women were seen,

$1,944(48 \%)$ were AMA, and

$869(45 \%)$ women who were

AMA had PDT (Figure 1).

The review covering the

2007-2009 period for all UT

associated clinics showed the

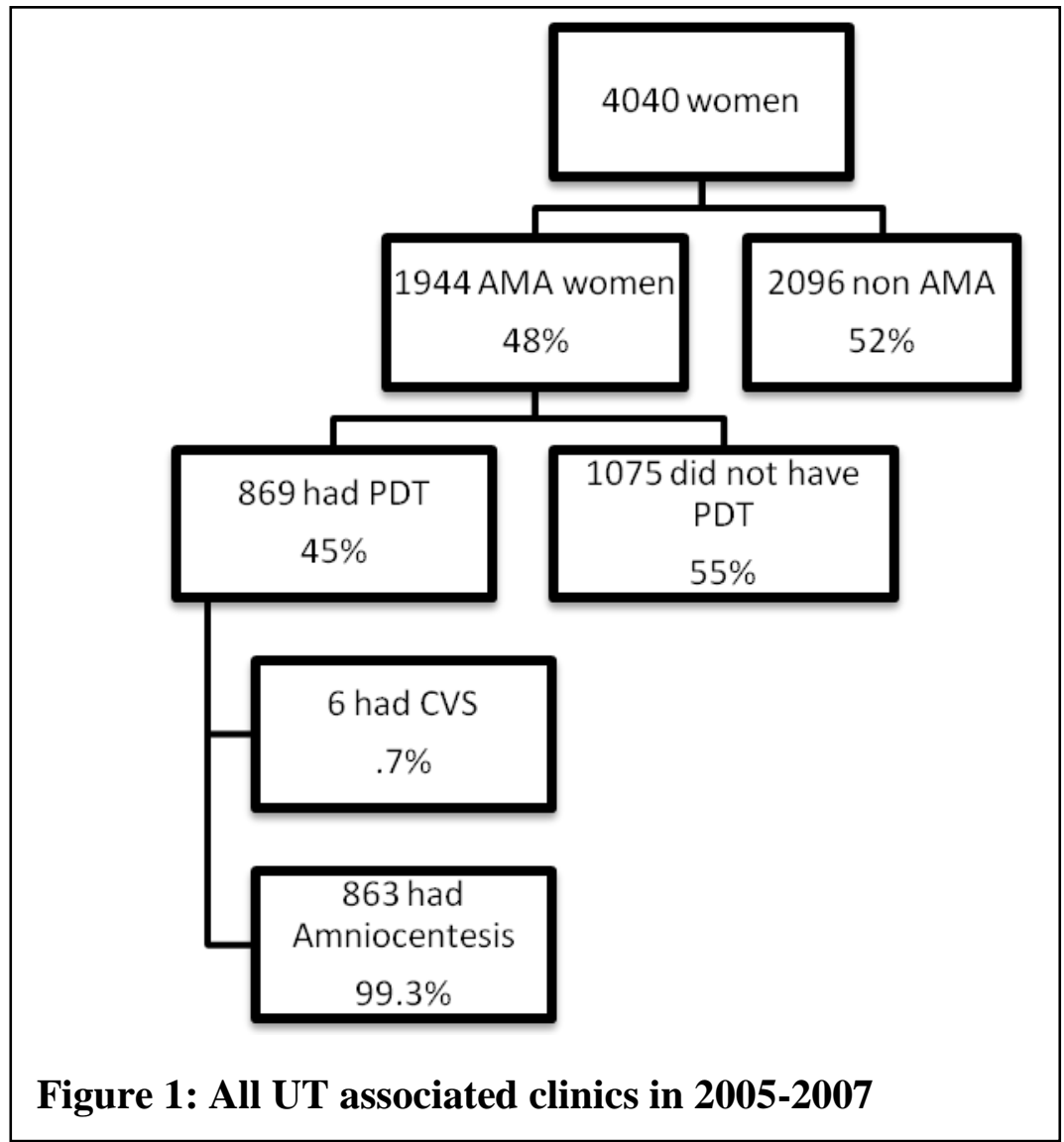

Figure 1: All UT associated clinics in 2005-2007

following: 4,315 women were seen, 2,110 (48.9\%) were AMA, and 740 (35\%) women who were AMA had PDT (Figure 2). 


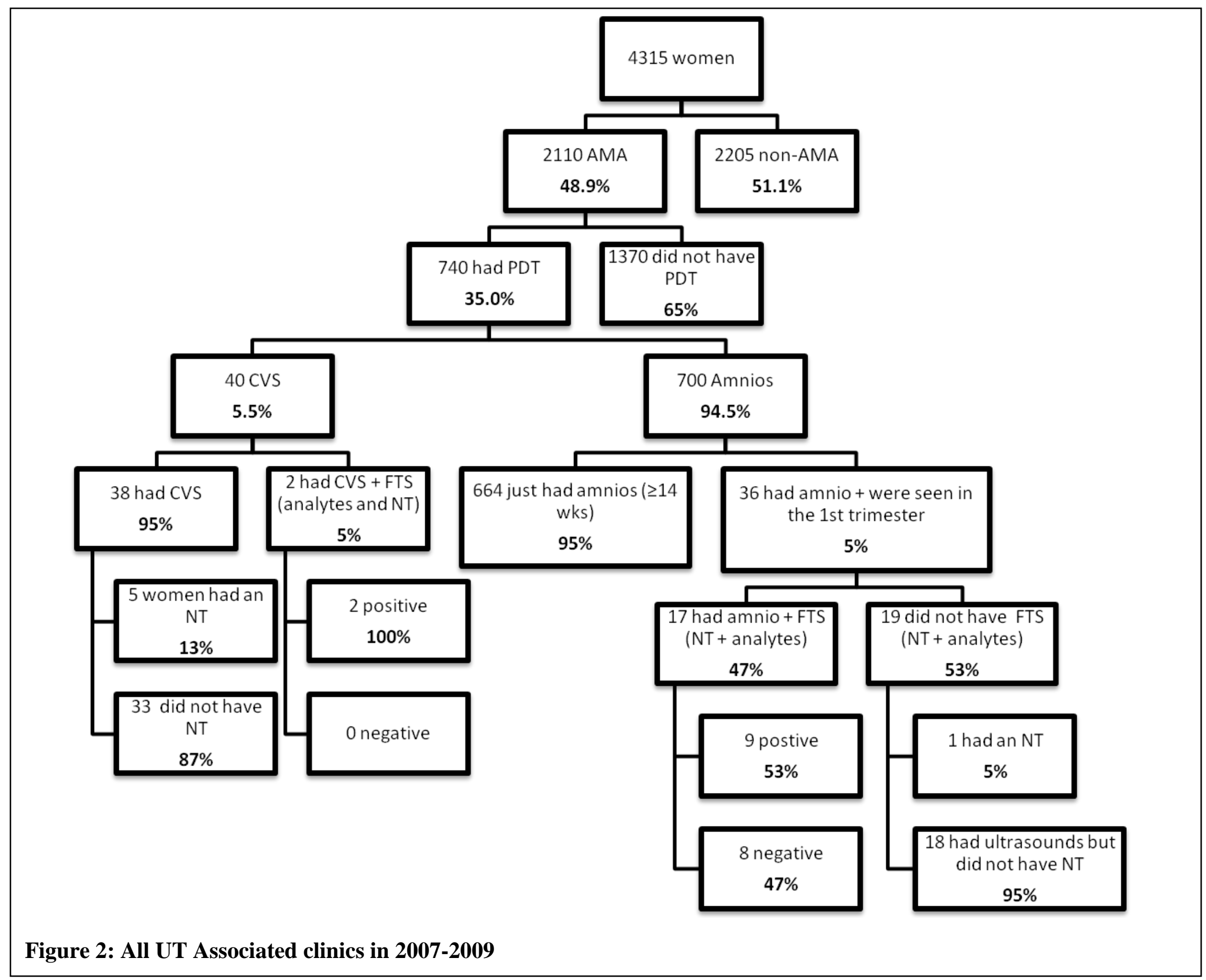




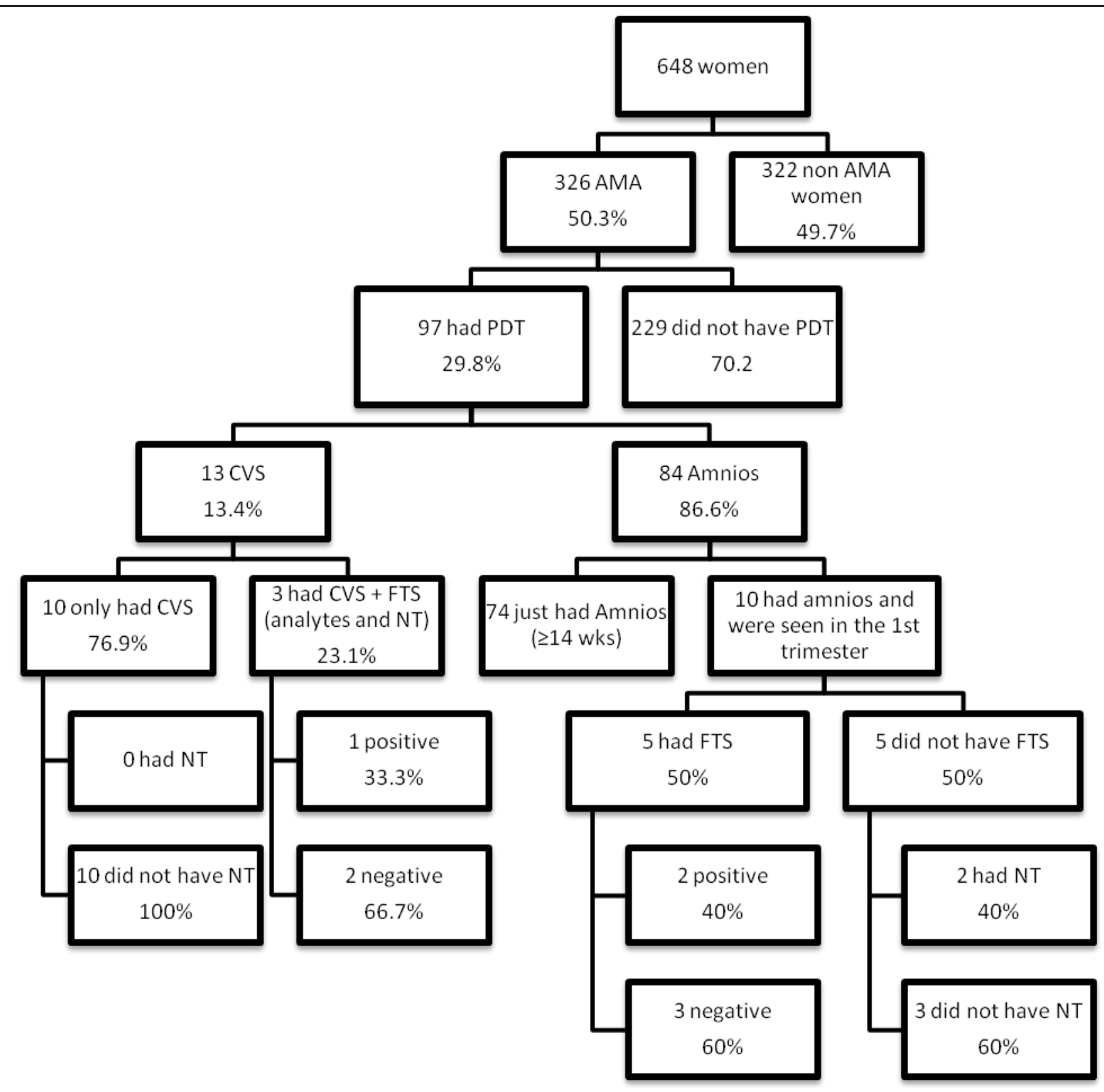

Figure 3: UTPB, MHMC, MHSW in September 2009-March 2010 


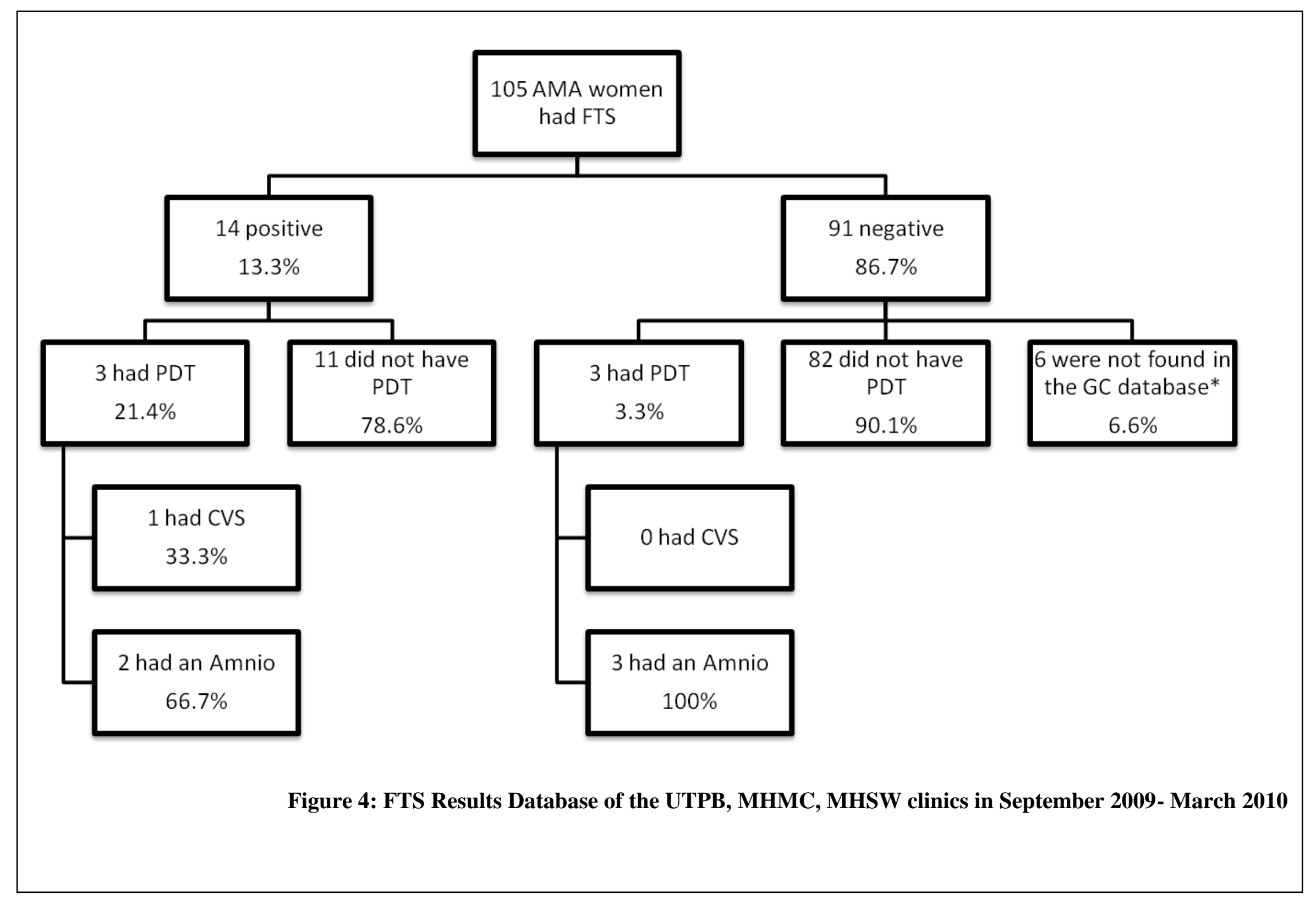


The third period review (September 2009 to March 2010) yielded the following: 648 women were seen, 326 (50.3\%) were AMA, and 97 (29.8\%) women who were AMA had PDT (Figure 3). The FTS database showed that 105 women were AMA and eligible for this study during the study period. Of those women, $14(13.3 \%)$ had positive results, $91(86.7 \%)$ had negative results, and $6(5.7 \%)$ women had PDT (Figure 4$)$. We also determined how many women who are AMA and had PDT were seen at UTPB, MCMH, and MHSW in both of the time periods (Figure 5 and 6). Finally we abstracted the uptake rate of PDT in 20052007, 2007-2009 (which was broken down further to each year individually), and our study collection period (Figure 7).

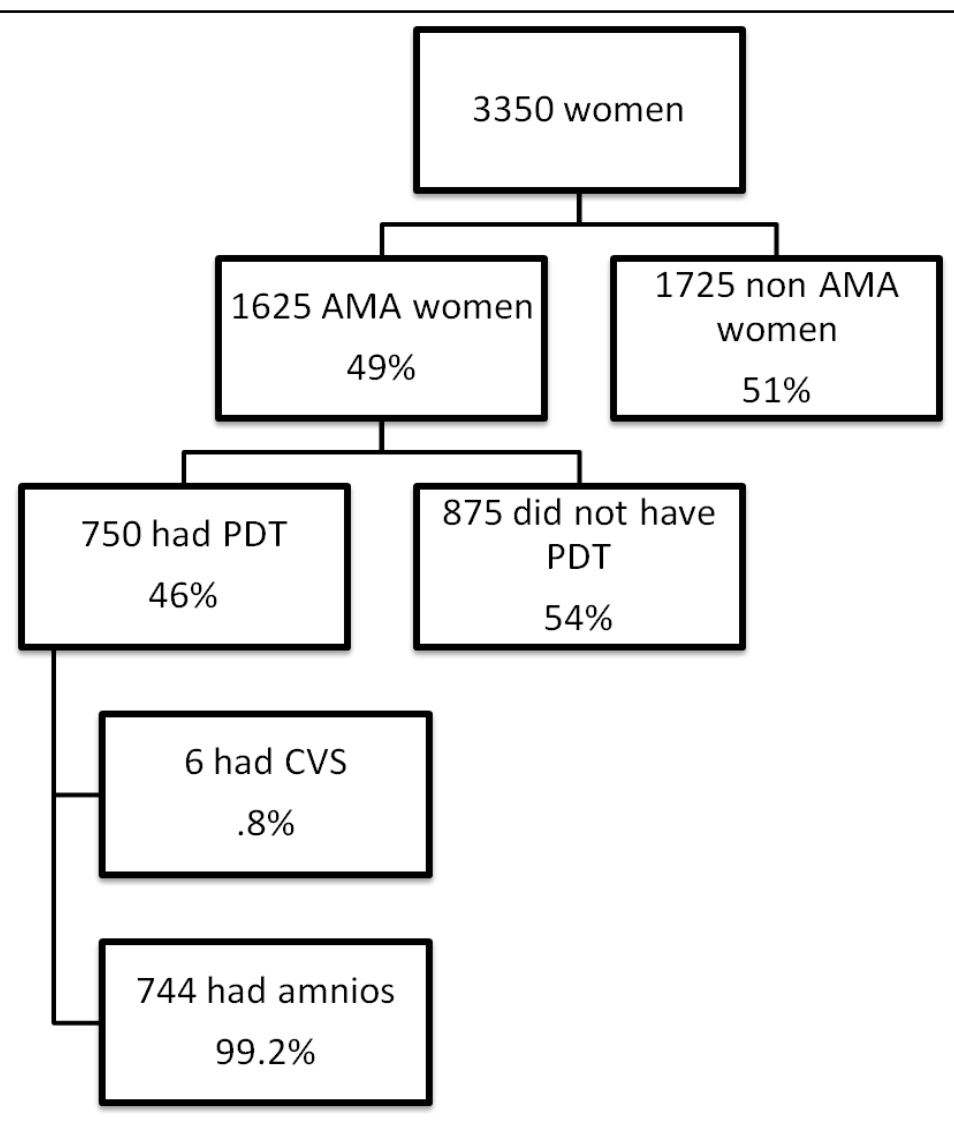

Figure 5: UTPB, MHMC, MHSW in 2005-2007 


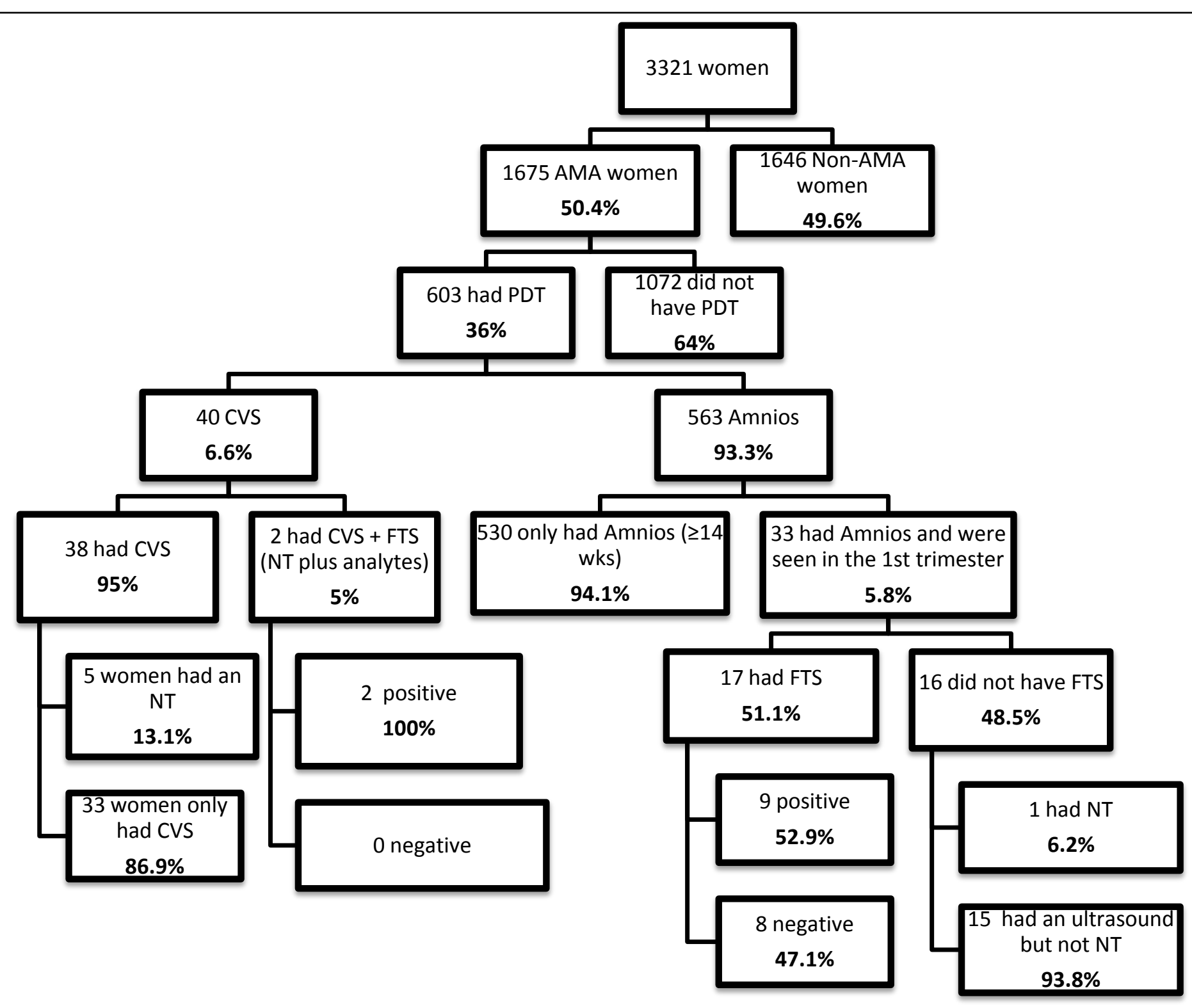

Figure 6: UTPB, MHMC, MHSW in 2007-2009 


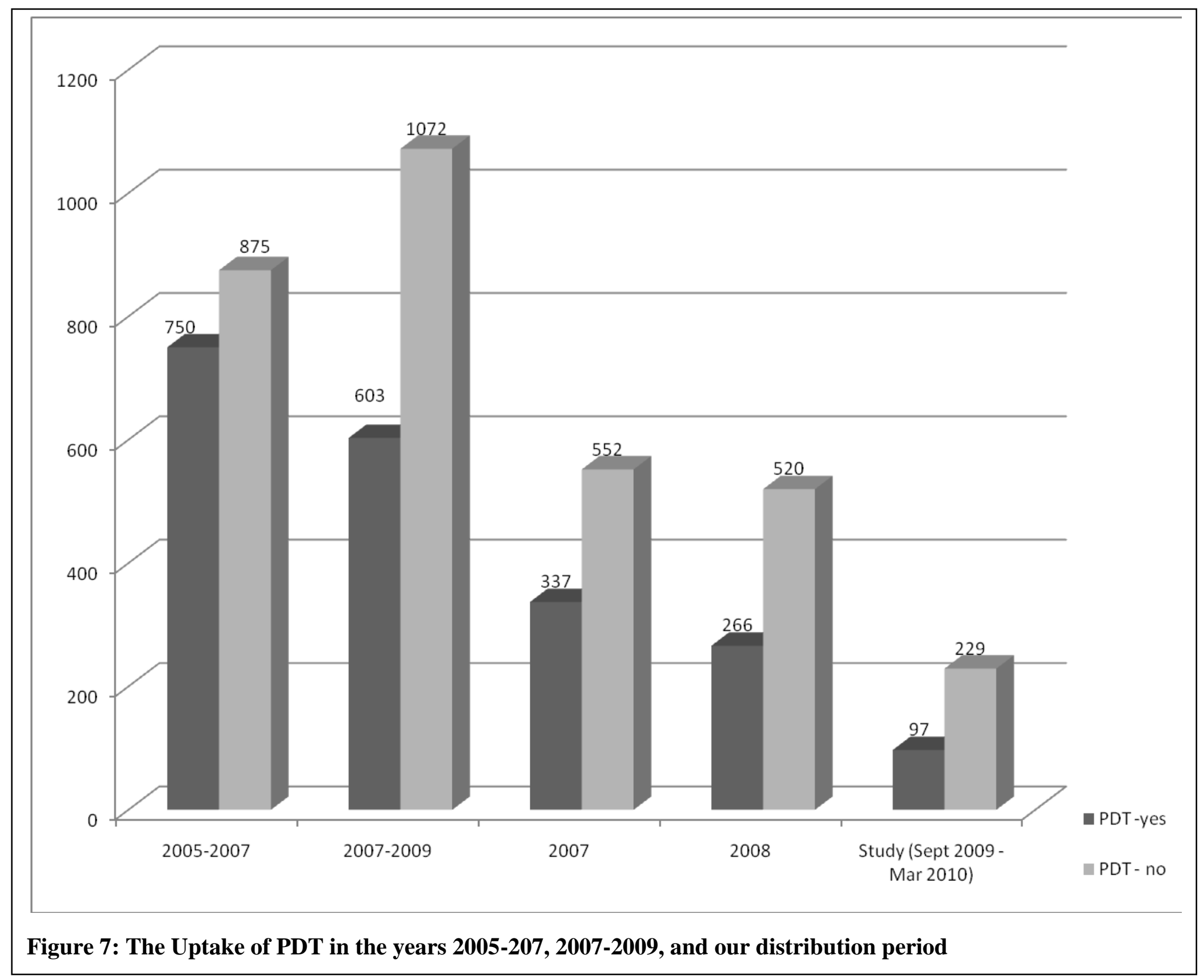


We collected 57 pre-counseling and 55 post-counseling surveys during our six month distribution period. We determined that 53 participants completed both the pre- and postcounseling survey (50.4\% response rate). We were able to distribute 49 physician surveys (one survey was returned undelivered) and 23 were completed (46.9\% response rate).

\section{$\underline{\text { Database Review }}$}

Our results indicate that while there was an increase in the number of AMA women in the 2007 to 2009 time period compared to the 2005 to 2007 period, there was a decrease in the amount of PDT performed in the 2007 to 2009 period. Between January 1, 2005 and December 31, 2006, 1,944 AMA women were seen (Figure 1). Of those women, 869 (80.8\%) had a CVS or amniocentesis. Between January 1, 2007 and December 31, 2008, 2,110 AMA women were seen (Figure 2). Of these women, only 740 (35\%) had a CVS or amniocentesis. This represents a $14.8 \%$ decrease in the number of PDT procedures performed at all UT associated clinics $(\mathrm{p}=<0.001)$ (Figure $1 \& 2)$. We also determine that there was a significant decrease (19.6\%) in the amount of PDT procedures performed at our three specified clinics when we compared these time periods $(\mathrm{p}=<0.001)$ (Figure $5 \& 6$ ).

We evaluated the database to determine what the indications were for the women that had PDT. Of the 740 women who had PDT between January 1, 2007 and December 31, 2008, 19 (2.5\%) had FTS prior to PDT (Figure 2). Further investigation found an additional six women to have had an elevated NT ( $>3.0 \mathrm{~mm})$ without being followed by any additional analyte testing. All of these six women with an elevated NT went on to have PDT (5 CVS \& 1 Amniocentesis). Therefore, 25 (3.3\%) women who were AMA and seen 
initially between 11 and 14 weeks elected to have first trimester screening (NT or NT +analytes) followed by PDT.

Between September $1^{\text {st }}, 2009$ and March $1^{\text {st }}, 2010,326$ AMA women were seen (Figure 3). We determined that eight (8.2\%) of the 97(29.7\%) women who had PDT, initially had FTS. It was also determined that an additional two women had an elevated NT, and went on to have PDT. Therefore, 10 (10.3\%) women had FTS (NT or NT +analytes) followed by PDT. There were 105 women who underwent genetic counseling for AMA, had FTS, and were seen during our distribution period at UTPB, MCMH and MHSW. There were 14 positive and 91 negative FTS results (Figure 4). Within the positive result category, three (21.4\%) women had PDT and eleven (78.5\%) women did not. Within the negative result category three $(3.2 \%)$ women who had PDT, $82(90.1 \%)$ women did not, and six individuals were not found in the prenatal database (Figure 4).

\section{Patient Survey}

A total of 112 patient surveys were collected; 57 pre-counseling and 55 postcounseling surveys. There were 53 women who completed both the pre- and postcounseling survey. The participants primarily included women who had an unspecified Caucasian ethnic background (39\%), at least a college education (93\%), and an annual household income of over $\$ 75,000$ (70\%) (Figures 8a-d \& 9a-c). Eighteen (31\%) of our participants have been pregnant at least three times, and $26(45 \%)$ women had at least one living child (Figure 8b-c). About 1\% (one respondent) of those surveyed has had a child with a genetic syndrome and about 5\% (3 respondents) have had a relative with a genetic 
syndrome (Figure 10a-b). Forty-nine (85\%) reported that they have not had PDT, while 3 participants (5\%) stated that they have had PDT during a previous pregnancy (Figure 10c).
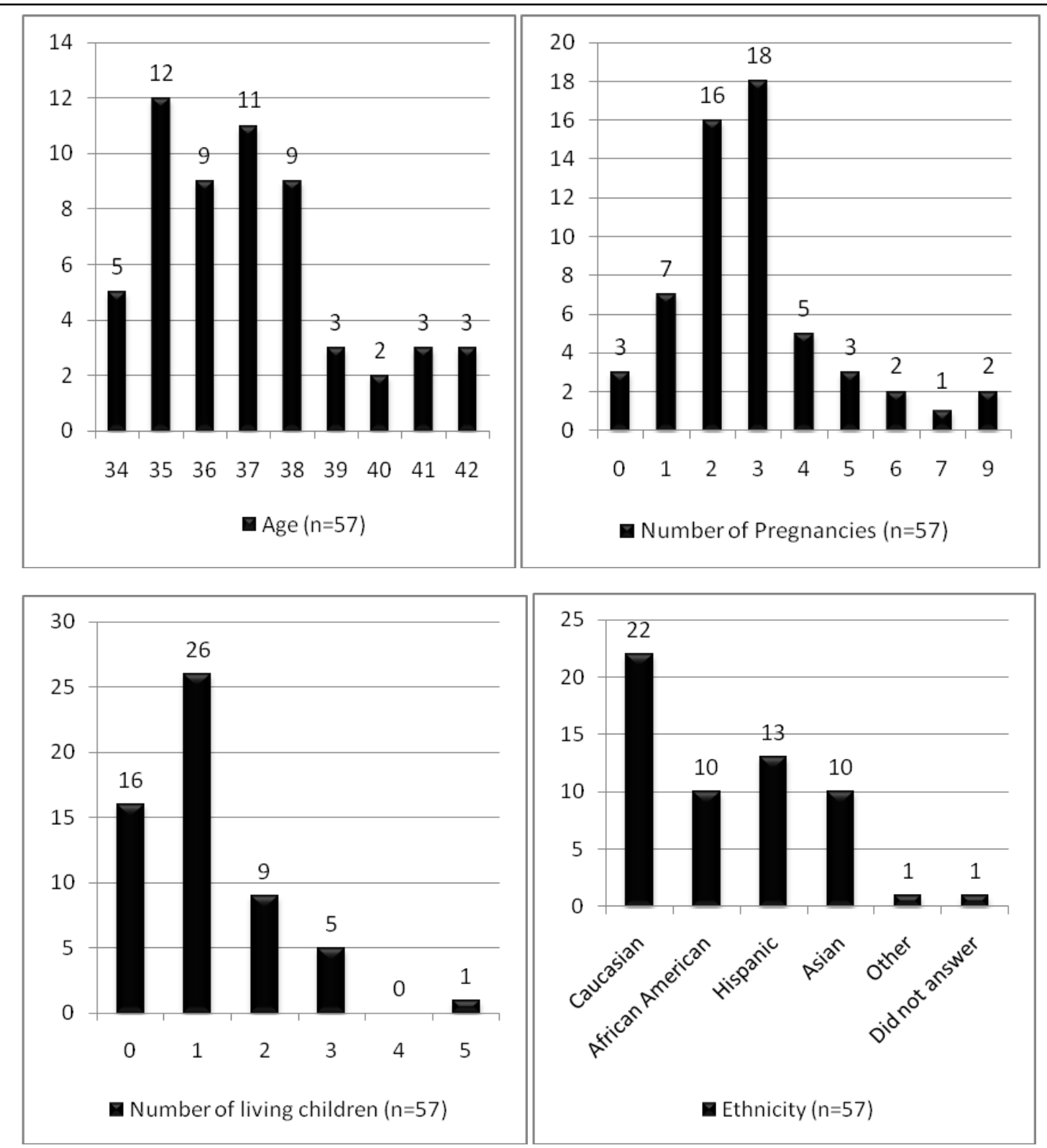

Figure 8: The age, number of pregnancies, number of living children, and ethnicity of our survey participants 


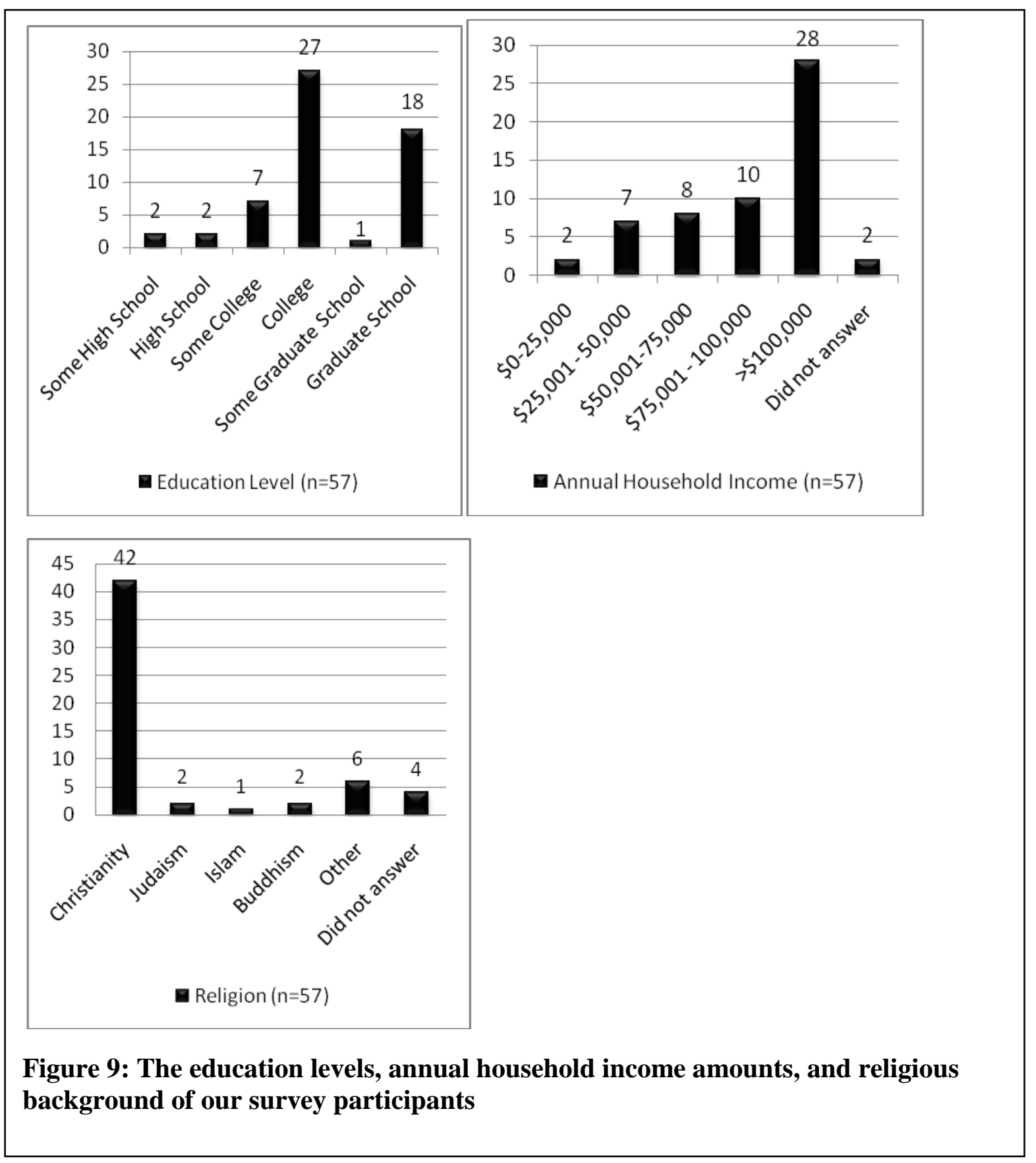




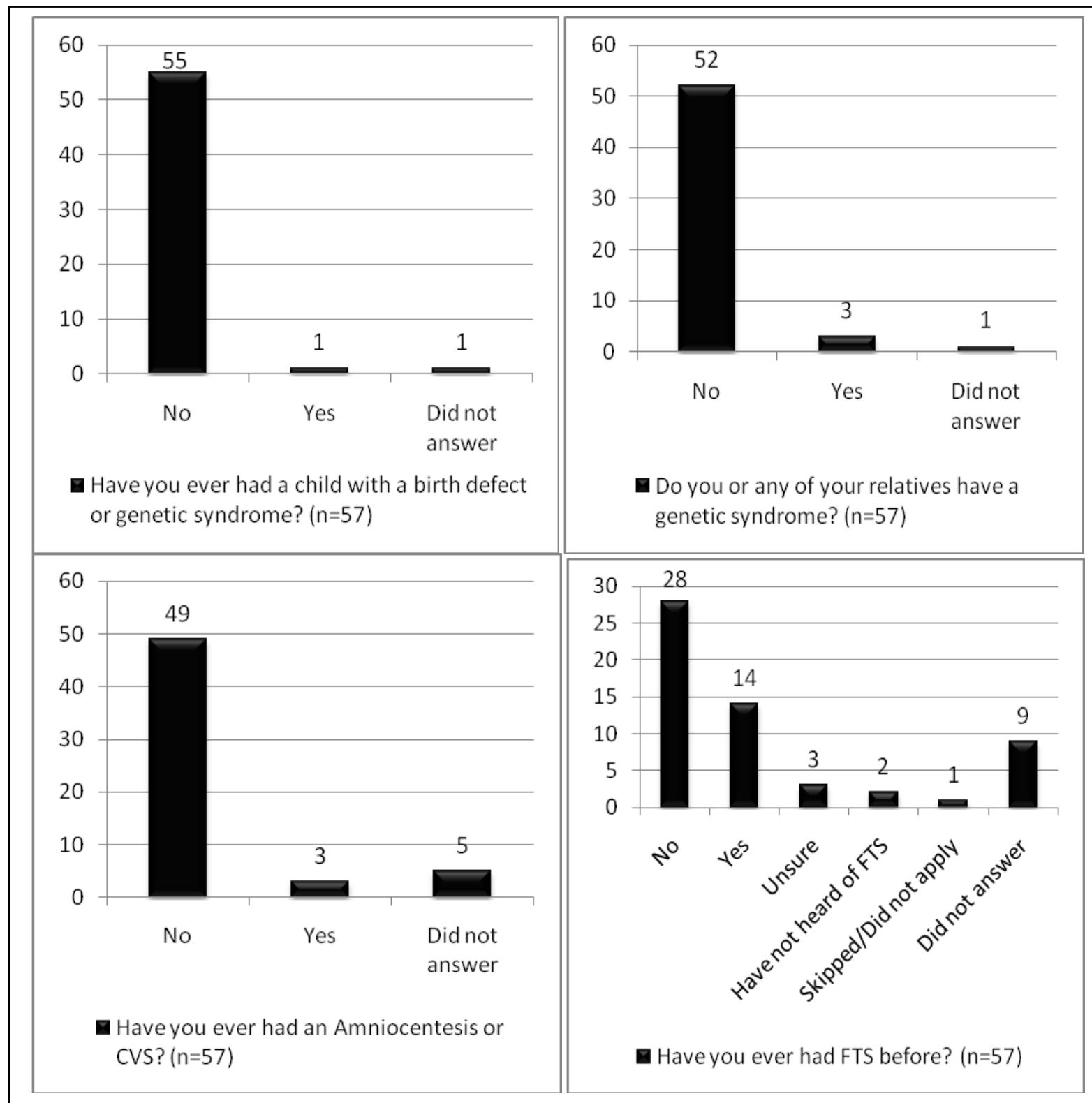

Figure 10: Determining participants' experiences with genetic syndromes, PDT, and FTS 
Table 1: Participant responses for how many individuals a person has spoken to about FTS

\begin{tabular}{|l|c|c|}
\hline \multicolumn{2}{|l|}{$\begin{array}{l}\text { Have you discussed FTS with anyone? } \\
(\mathrm{n}=57)\end{array}$} \\
\hline $\begin{array}{l}\text { How many } \\
\text { people have } \\
\text { you spoken } \\
\text { to? }\end{array}$ & Count & Percent \\
\hline No One & 12 & $21.05 \%$ \\
\hline 1 Person & 32 & $56.14 \%$ \\
\hline 2 People & 0 & $0 \%$ \\
\hline 3 People & 6 & $10.53 \%$ \\
\hline 4 People & 1 & $1.75 \%$ \\
\hline $\begin{array}{l}\text { Did not } \\
\text { Answer }\end{array}$ & 6 & $10.53 \%$ \\
\hline
\end{tabular}

\section{Most patients}

(59.6\%) had never heard of

FTS before, though when

asked if they had spoken to

someone about FTS, 32

respondents (56\%) said that

they spoke to at least one

person (Figure 10d \& Table

1). Of those women who

spoke to at least one person

(39 respondents), $82 \%$ (32

respondents) stated that the

one person they spoke to

was their OB/GYN (Figure

11). Among our participants

44 (77\%) believed that FTS could not be done instead of PDT and $37(65 \%)$ believed that it would provide information only about a specific chromosome problem (Table 2). Ten (18\%) and 30 respondents (53\%) also believed that FTS could be done instead of PDT and that it would inform them on the risk for birth defects, respectively (Figure 9). When asked if they planned to have PDT prior to learning about FTS, 11 (19\%) said "yes", $17(30 \%)$ were "undecided", and 21 (37\%) said "no" (Table 3). 


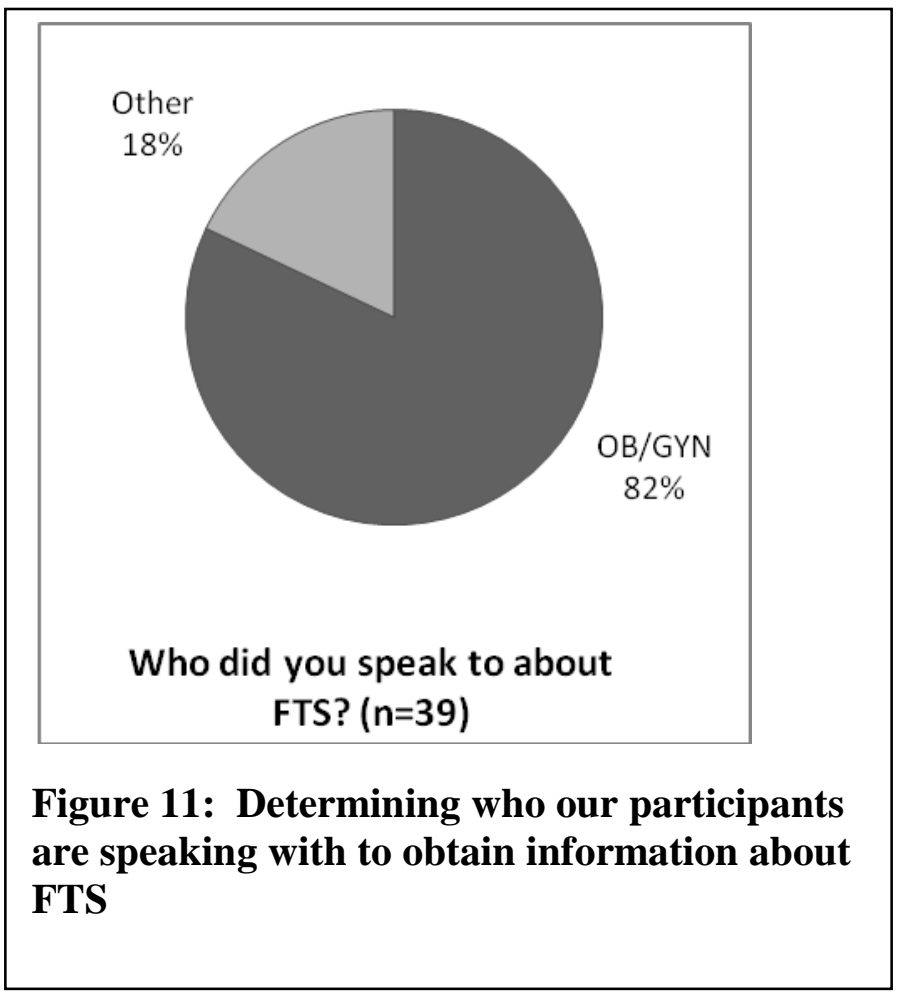

The vast majority of our participants $50(91 \%)$ knew that there was an age related risk for fetal aneuploidy prior to their genetic counseling session (Figure 12). After their session, 49 (89\%) understood that FTS was used to determine a person's risk to have a baby with trisomy 21 or trisomy 18 , while $21(38 \%)$ also believed it would inform them on the risk of birth defects (Table 4). When asked to rank the reasons, in order of importance to them, for having FTS, $57 \%$ of patients ranked 3a,"I want to obtain information early in the pregnancy about the risk for specific chromosomal abnormalities, like trisomy 21 (Down syndrome)", as their number one reason to have FTS (Figure 13). The next two top ranked responses were 3b, "It will help me to determine if I want to have an amniocentesis or CVS" and 3c, "I want to be prepared for the possibility of a baby with a chromosomal abnormality like trisomy 21 (Down syndrome)". These responses were ranked number one $23 \%$ and $15 \%$ of the time, respectively (Figure 13). 


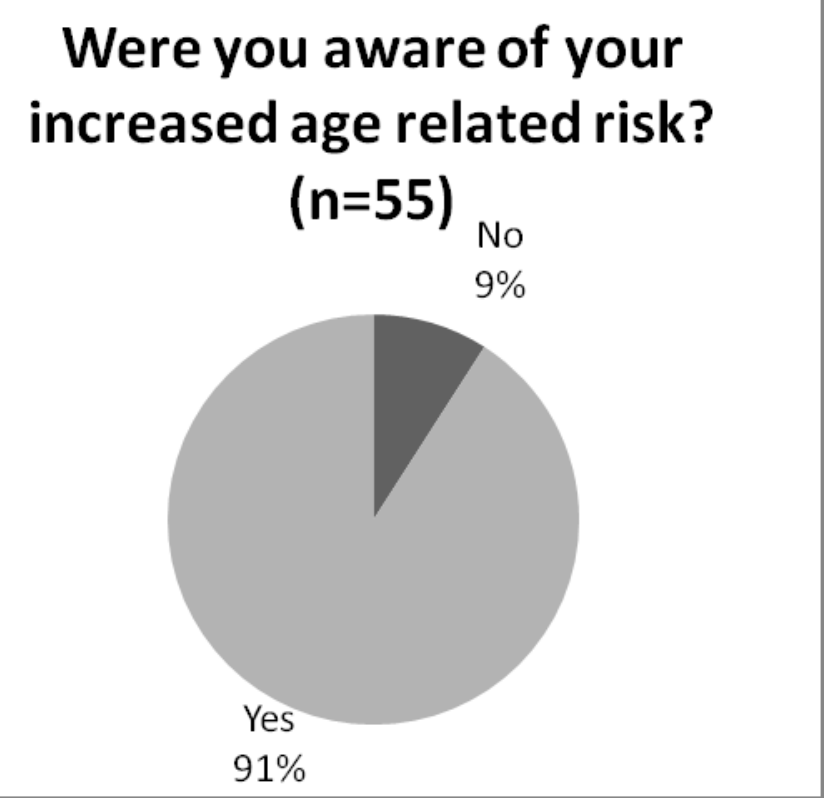

Figure 12: Understanding if our participants were aware of their increased age-related risk for fetal aneuploidy

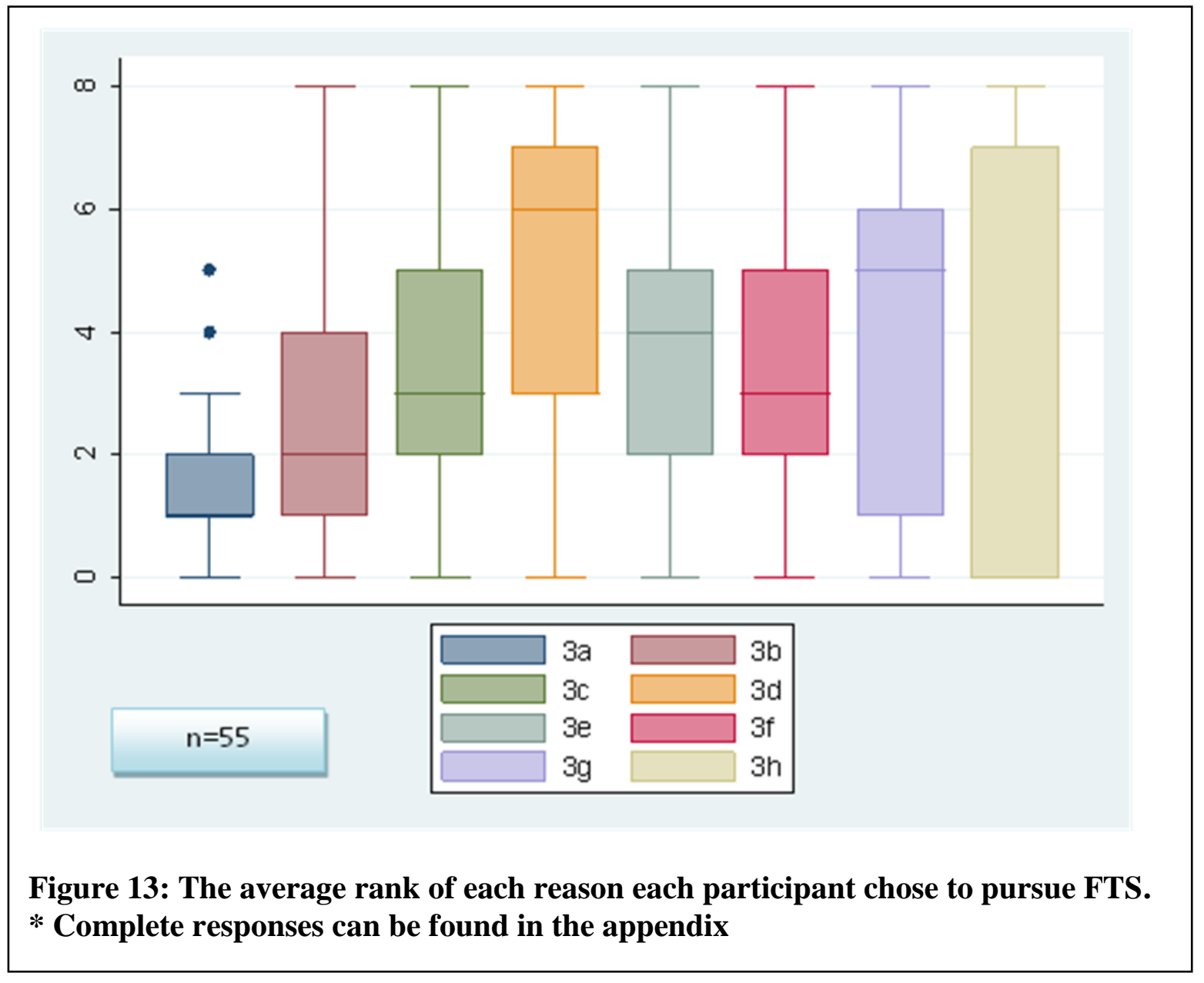


Table 2: Determining participant understanding of FTS prior to their genetic counseling session

\begin{tabular}{|l|l|}
\hline \multicolumn{2}{|c|}{ Prior to having FTS, what do you believe FTS tell you? (n=57) } \\
*Participants could choose more than one answer* \\
\hline Answer & Percent that said "Yes" \\
\hline It can be done instead of an amniocentesis or CVS & $18 \%$ \\
\hline $\begin{array}{l}\text { It can tell me the chance for the baby to have a birth } \\
\text { defect }\end{array}$ & $53 \%$ \\
\hline $\begin{array}{l}\text { It can tell me the risk for my baby to have a specific } \\
\text { chromosome problem }\end{array}$ & $65 \%$ \\
\hline It can tell me if the baby is healthy & $23 \%$ \\
\hline I have not heard of FTS/Other & $14 \%$ \\
\hline
\end{tabular}

Table 3: Participants' stated intentions regarding PDT prior to their genetic counseling session

\begin{tabular}{|l|l|l|}
\hline $\begin{array}{l}\text { Were you planning to have an Amniocentesis or CVS, prior to learning about FTS? } \\
(\mathrm{n}=57)\end{array}$ & Count & Percent \\
\hline Answer & 11 & $19.3 \%$ \\
\hline Yes & 17 & $29.82 \%$ \\
\hline Undecided & 21 & $36.84 \%$ \\
\hline No & 2 & $3.51 \%$ \\
\hline I have not heard of FTS & 2 & $3.51 \%$ \\
\hline $\begin{array}{l}\text { I have not heard of CVS or } \\
\text { amniocentesis }\end{array}$ & & $7.01 \%$ \\
\hline Other/Did not answer & 4 & \\
\hline
\end{tabular}




Table 4: Determining what the patient understood about FTS after their genetic
counseling session
\begin{tabular}{|l|l||}
\hline $\begin{array}{l}\text { After you're genetic counseling session what did you learn about FTS? (n=55) } \\
\text { *Participants could choose more than one answer* }\end{array}$ \\
\hline Answer & Percent that said "Yes" \\
\hline $\begin{array}{l}\text { That it could tell me my risk for my baby to have Trisomy } 21 \\
\text { or Trisomy } 18\end{array}$ & $89 \%$ \\
\hline $\begin{array}{l}\text { That it could tell me if anything could possibly be wrong } \\
\text { with my baby }\end{array}$ & $24 \%$ \\
\hline That it could tell me the risk that my baby has a birth defect & $38 \%$ \\
\hline I do not know what FTS will be able to tell me/Other & $2 \%$ \\
\hline
\end{tabular}




\begin{tabular}{|c|c|}
\hline \multicolumn{2}{|c|}{$\begin{array}{l}\text { Table 5: Participant intentions toward PDT after th } \\
\text { received genetic counseling }\end{array}$} \\
\hline \multirow{2}{*}{\multicolumn{2}{|c|}{$\begin{array}{l}\text { Are you going to have an Amniocentesis or } \\
\text { CVS? (n=55) } \\
\text { *Participants could choose more than one } \\
\text { answer* }\end{array}$}} \\
\hline & \\
\hline Answer & $\begin{array}{l}\text { Percent that } \\
\text { said "Yes" }\end{array}$ \\
\hline $\begin{array}{l}\text { I will use my FTS results to } \\
\text { decide }\end{array}$ & $82 \%$ \\
\hline No, under no circumstance & $5 \%$ \\
\hline $\begin{array}{l}\text { Yes, no matter what my } \\
\text { results say }\end{array}$ & $9 \%$ \\
\hline $\begin{array}{l}\text { Yes, if my insurance will } \\
\text { cover it }\end{array}$ & $2 \%$ \\
\hline $\begin{array}{l}\text { I have not heard of } \\
\text { amniocentesis or CVS/Other }\end{array}$ & $2 \%$ \\
\hline
\end{tabular}

When
completing the post-
counseling survey, 45
(82\%) of participants
said that they would
use their results to help
make their decision
regarding PDT (Table
5). Based on the pre-
counseling survey,
eleven individuals
wanted PDT, seventeen
were undecided, and 21
did not want PDT

(Table 3). After genetic counseling, seven people indicated that they wanted PDT, 31

people were undecided, and only one person did not want PDT (Figure 14). We found that individuals, who initially did not want to have PDT, became more open to considering PDT and changed their response to "undecided" after their genetic counseling session. Those who were initially undecided remained so, and those who initially wanted to have PDT also still wanted to have PDT, although there was one participant who initially wanted PDT and then became "undecided". We also determined that many individuals may not have had a solid plan regarding PDT, and wanted to use their FTS results to assist them in deciding about PDT (Table 6). 


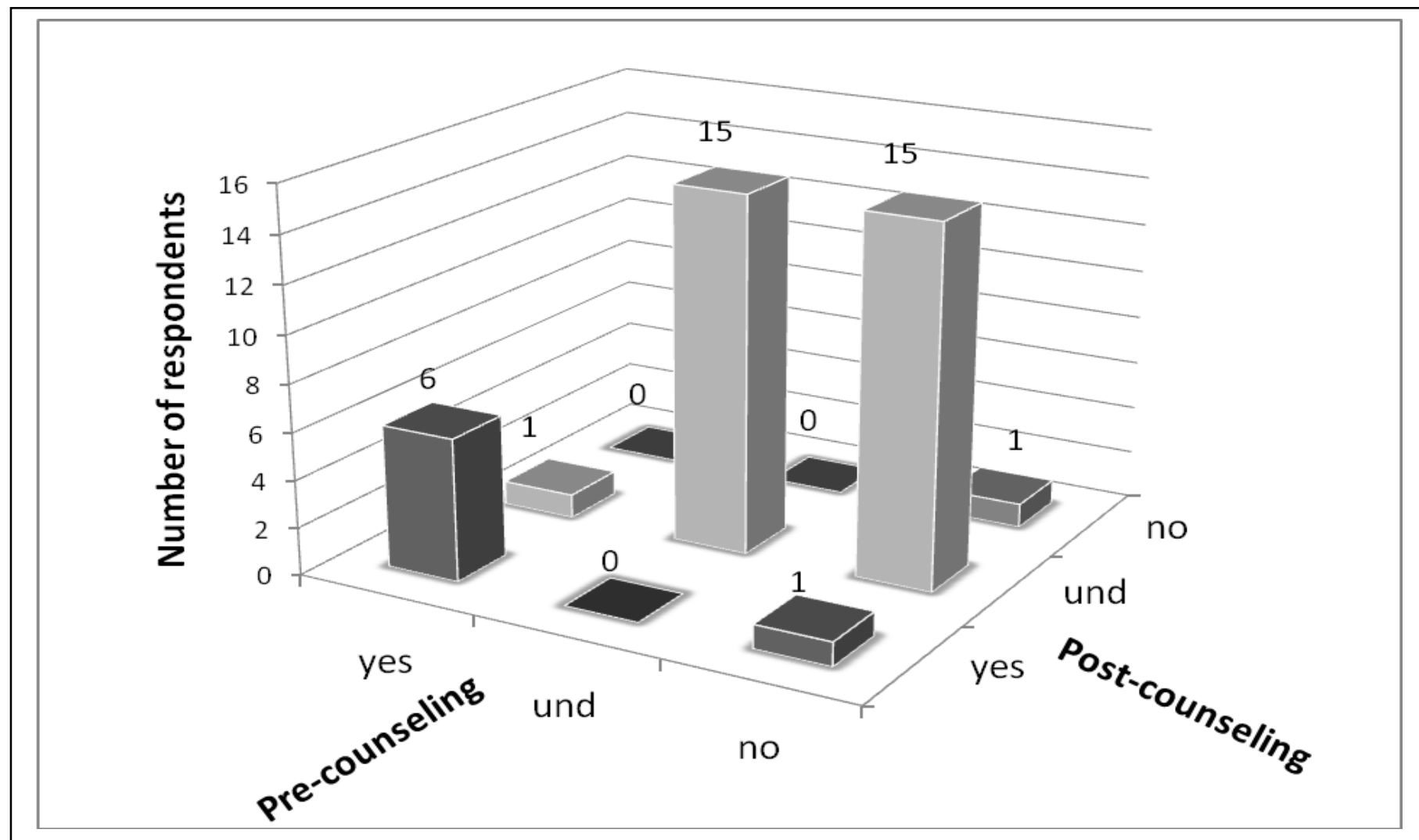

Figure 14: Understanding if the participants' plan regarding PDT changed since their genetic counseling session 


\begin{tabular}{|c|c|c|}
\hline \multicolumn{3}{|c|}{ Did your plan to have an Amniocentesis or CVs change after learning about FTS? (n=55) } \\
\hline Answer & Count & Percent \\
\hline $\begin{array}{l}\text { Yes, after learning about FTS I no longer want } \\
\text { an amniocentesis or CVS }\end{array}$ & 0 & $0 \%$ \\
\hline $\begin{array}{l}\text { Yes, after learning about FTS I now want an } \\
\text { amniocentesis or CVS }\end{array}$ & 4 & $7.27 \%$ \\
\hline $\begin{array}{l}\text { No, I still do not want to have an } \\
\text { amniocentesis or CVS }\end{array}$ & 4 & $7.27 \%$ \\
\hline $\begin{array}{l}\text { No, after learning about FTS I still want to } \\
\text { have an amniocentesis or CVS regardless of } \\
\text { what my results are }\end{array}$ & 3 & $5.45 \%$ \\
\hline $\begin{array}{l}\text { I did not have a plan, I will decided about it } \\
\text { after I receive my results }\end{array}$ & 35 & 63.64 \\
\hline Undecided/Did not answer/Other & 9 & $16.35 \%$ \\
\hline
\end{tabular}

Table 7: The type of patients our participating physician refer to our clinics

\begin{tabular}{|l|l|}
\hline \multicolumn{2}{|c|}{ Who do you refer for FTS? (n=23) } \\
\hline Answer & $\begin{array}{l}\text { Percent that said } \\
\text { "Yes" }\end{array}$ \\
\hline All patients & $65 \%$ \\
\hline Only those who are AMA ( $\geq 35)$ & $26 \%$ \\
\hline Only patients who are $\leq 35$ & $0 \%$ \\
\hline Only those who would terminate & $13 \%$ \\
\hline Those with prior affected pregnancies & $13 \%$ \\
\hline
\end{tabular}




\section{$\underline{\text { Physician survey }}$}

Fifteen $(65 \%)$ of

the responders stated

that they referred all of

their patients for FTS,

with $6(26 \%)$ stating

that they referred only

their AMA patients

(Table 7). Participants

stated that they tell their

patients that FTS will

give them information

about trisomy 21 and
Table 8: How are patient informed about FTS

How do you routinely present the option of FTS to your patients? $(\mathrm{n}=23)$

*Participants could choose more than one answer*

\begin{tabular}{|l|l|}
\hline Answer & $\begin{array}{l}\text { Percent that said } \\
\text { "Yes" }\end{array}$ \\
\hline $\begin{array}{l}\text { I tell them that it can be done } \\
\text { instead of an amniocentesis or CVS }\end{array}$ & $17 \%$ \\
\hline $\begin{array}{l}\text { I tell them it will help them with } \\
\text { their decision about prenatal } \\
\text { diagnostic testing }\end{array}$ & $35 \%$ \\
\hline $\begin{array}{l}\text { I tell them that it will give them } \\
\text { information about Trisomy } 21 \text { and } \\
\text { Trisomy } 18\end{array}$ & $87 \%$ \\
\hline I give them a brochure & $35 \%$ \\
\hline
\end{tabular}

trisomy 18 (82\%), that FTS will help their decision regarding PDT 8 (35\%), and that FTS

can be done instead of PDT 4 (17\%) (Table 8). While 100\% of the respondents report

talking to their patients about FTS, $21(91 \%)$ believed that their patients did not know about

FTS prior to their discussion with them (Figure 15). Physicians who responded felt that

FTS was helpful to their patients ( $74 \%)$ and $22 \%$ believed that it was essential to their decision making process (Table 9). 


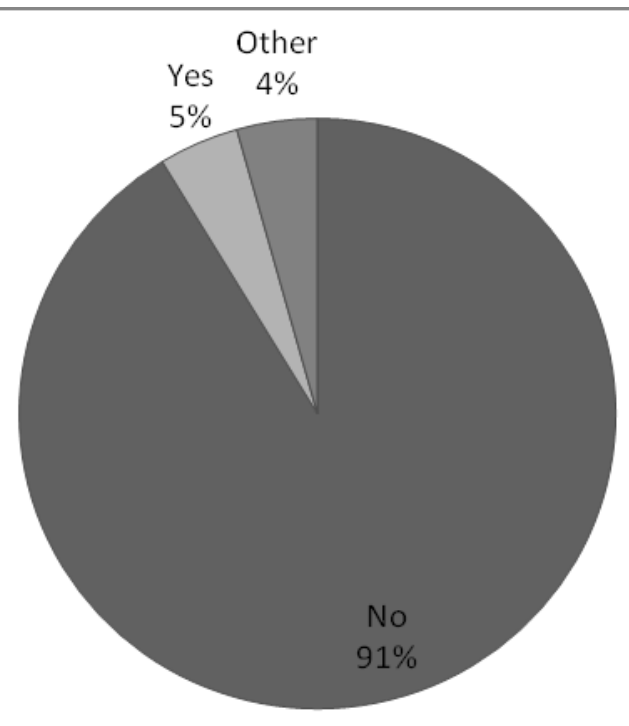

Do you think your patients know what FTS is?

Figure 15: Patient awareness of FTS prior to their OB/GYN appointment

Table 9: How do patients feel about FTS

How do your patients feel about FTS? (n=23)

*Participants could choose more than one answer*

\begin{tabular}{|l|l|}
\hline Answer & $\begin{array}{l}\text { Percent that said } \\
\text { "Yes" }\end{array}$ \\
\hline They feel that it is helpful & $74 \%$ \\
\hline $\begin{array}{l}\text { They feel that it is essential to their } \\
\text { decision making process }\end{array}$ & $22 \%$ \\
\hline They feel it does not help them & $4 \%$ \\
\hline $\begin{array}{l}\text { They feel it causes them worry and } \\
\text { anxiety }\end{array}$ & $13 \%$ \\
\hline They feel they didn't really need it & $13 \%$ \\
\hline I have not asked this question & $22 \%$ \\
\hline
\end{tabular}




\section{Confounding Factors}

The chi squared analysis performed on each of the possible confounding factors, for both the pre-counseling and the post-counseling survey, was not significant for any of the factors (Figures 16-21). We concluded that there was not an overall change in the patient's decision to accept or decline PDT that could be attributed to one of these factors. On the Wilcoxon signed rank test many confounding factors proved to be significant effect modifiers (Figures 22-29).

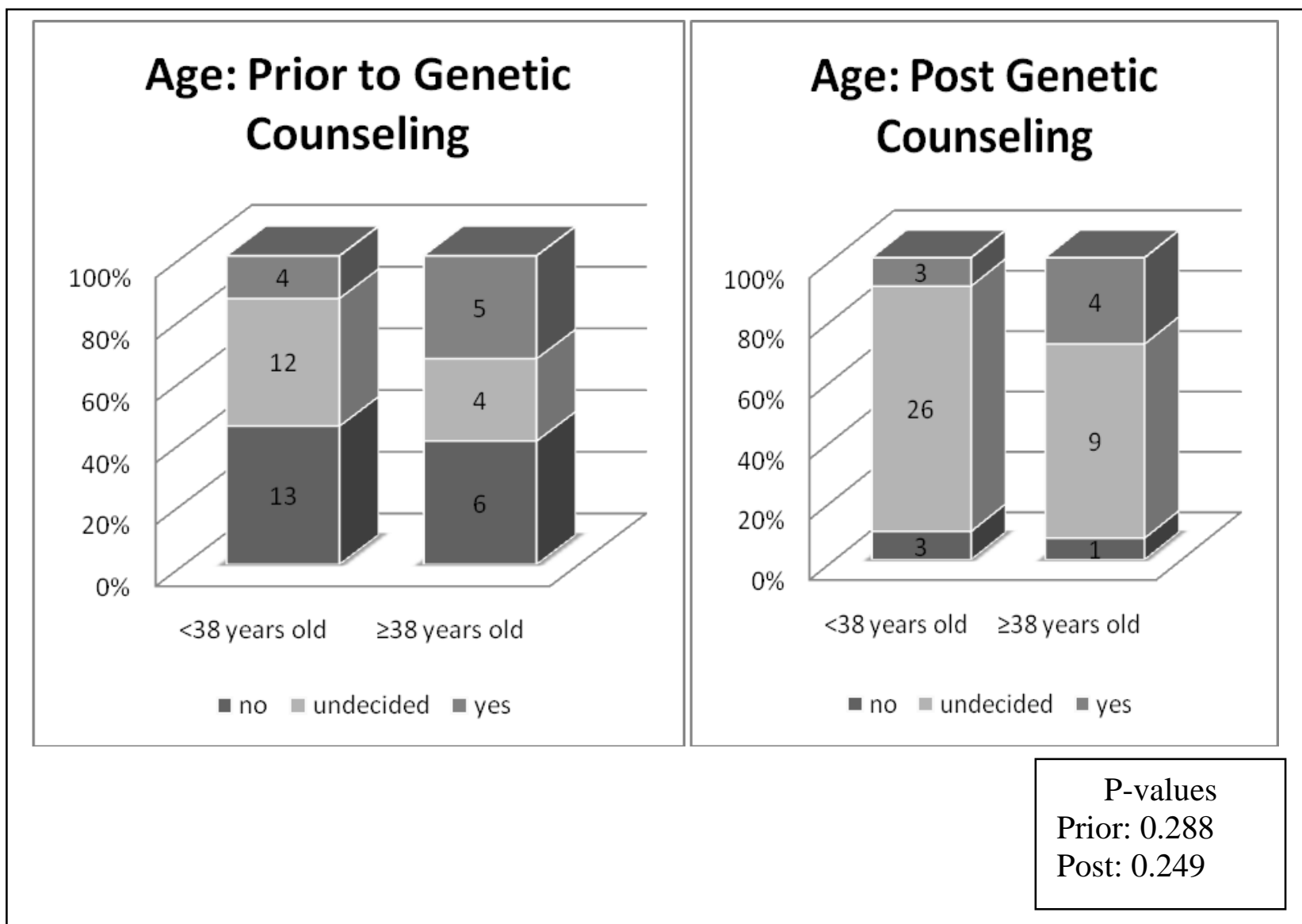

Figure 16: Change in the patient's plan according to age 


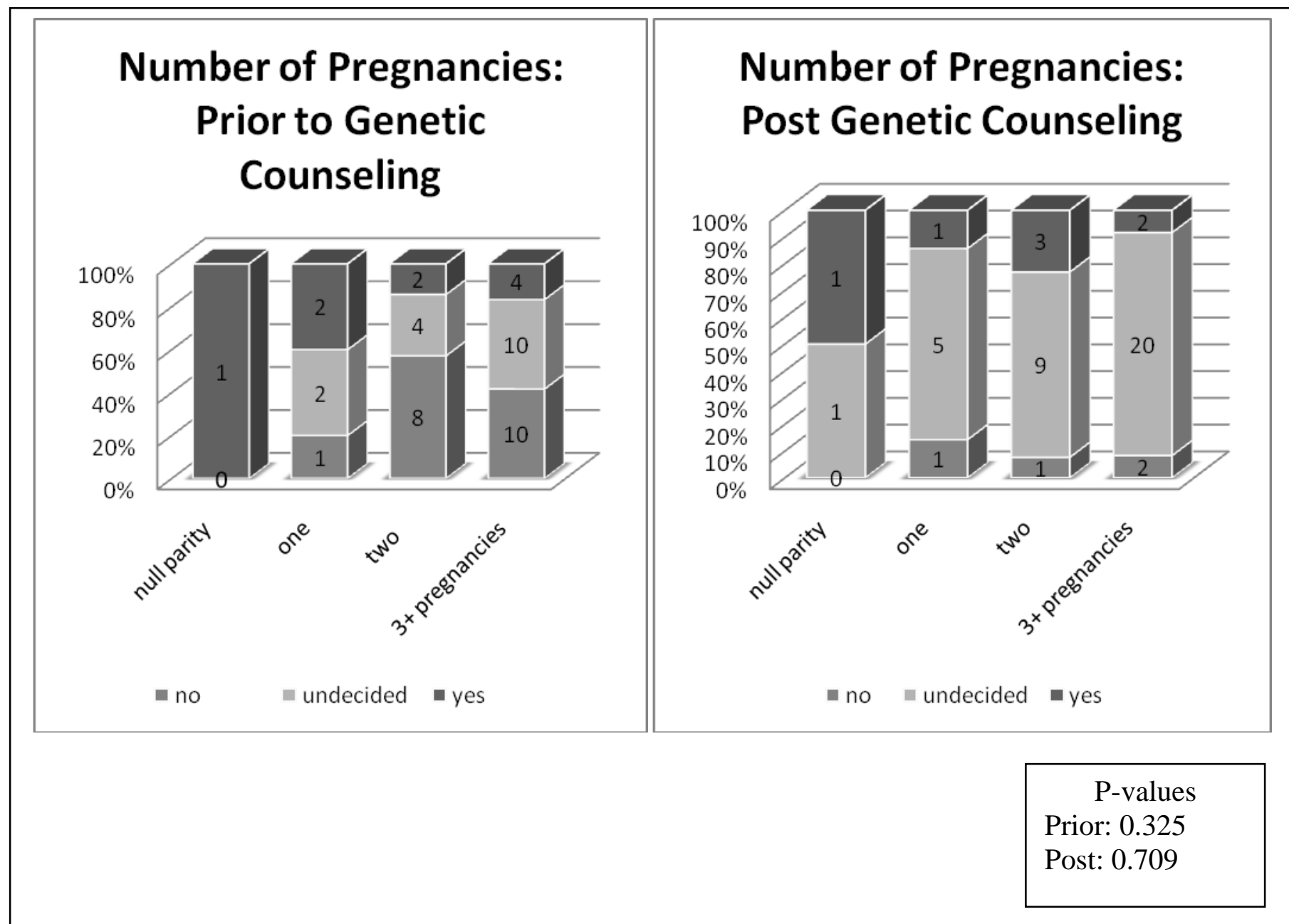

Figure 17: Change in patient's plan according to number of pregnancies 


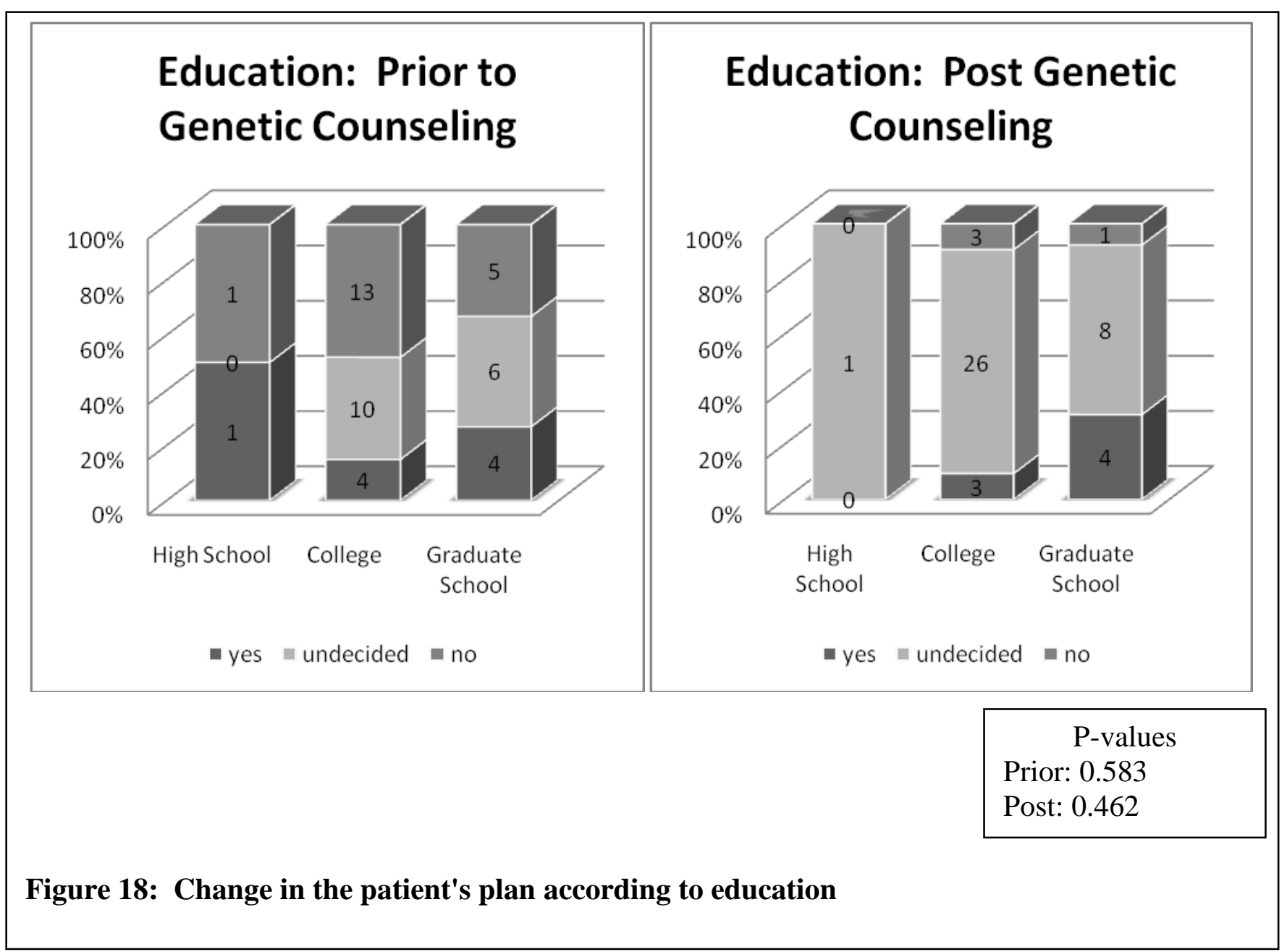




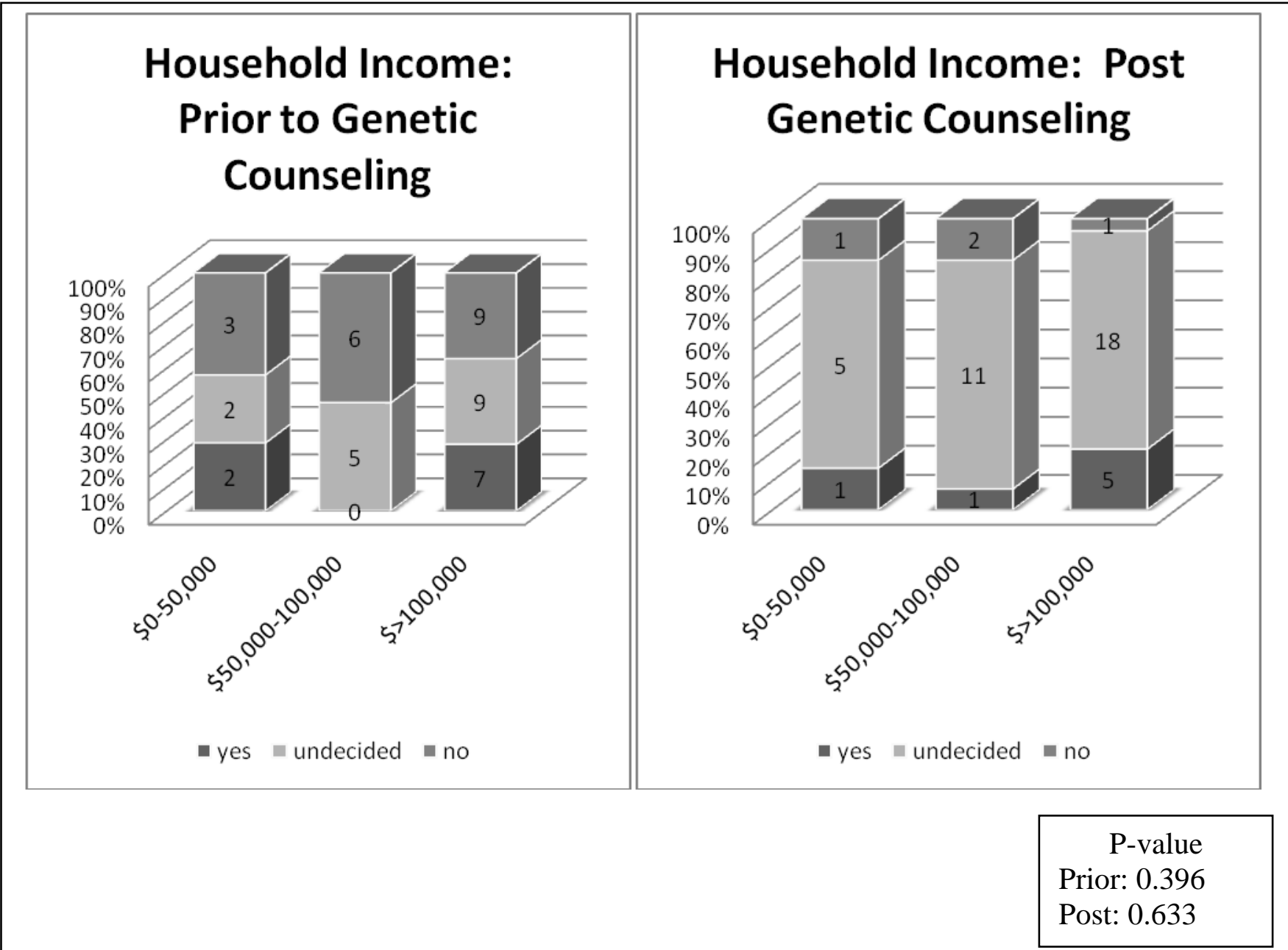

Figure 19: The change in the patient's plan according to household income 


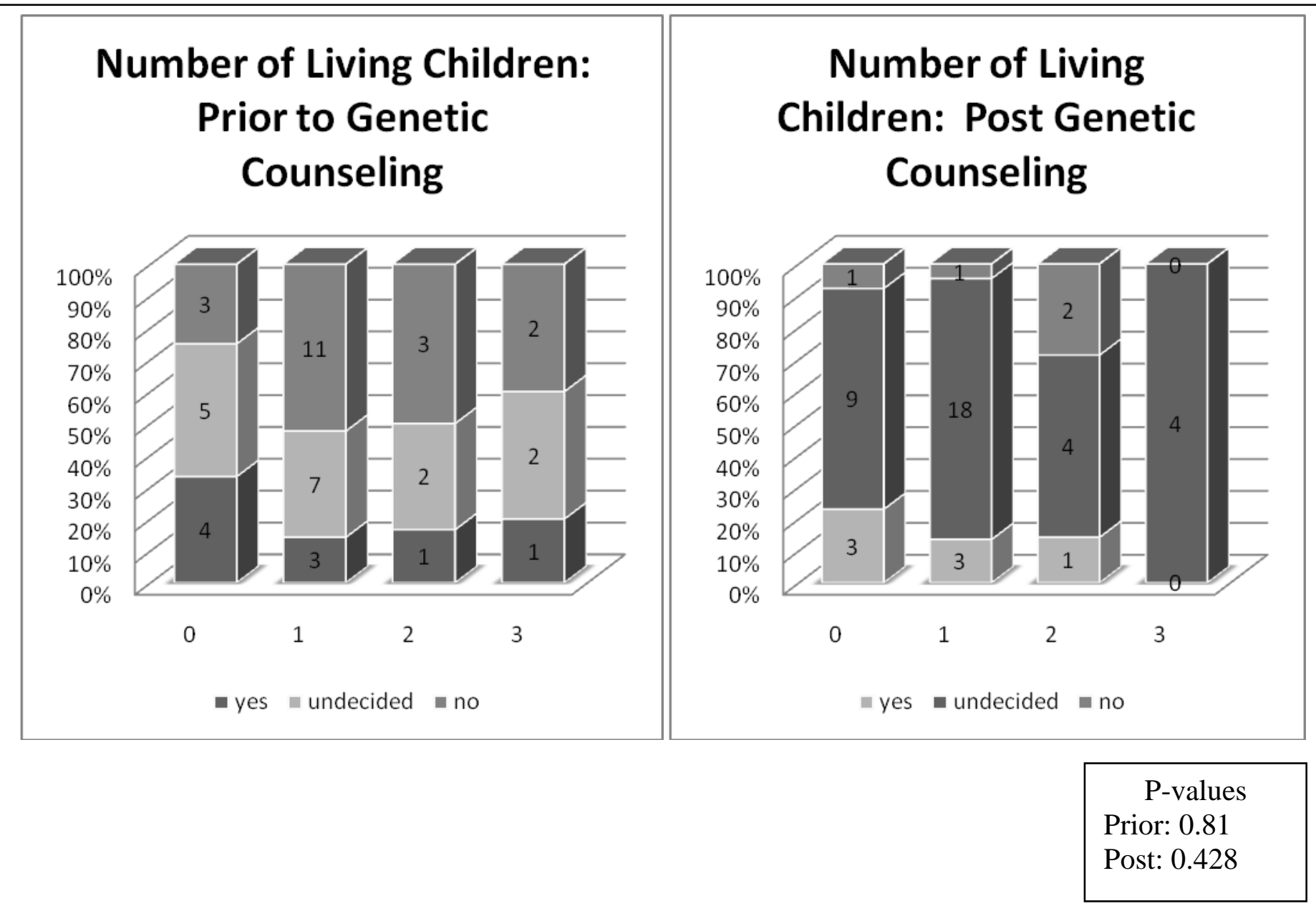

Figure 20: Change in the patient's plan according to number of living children 


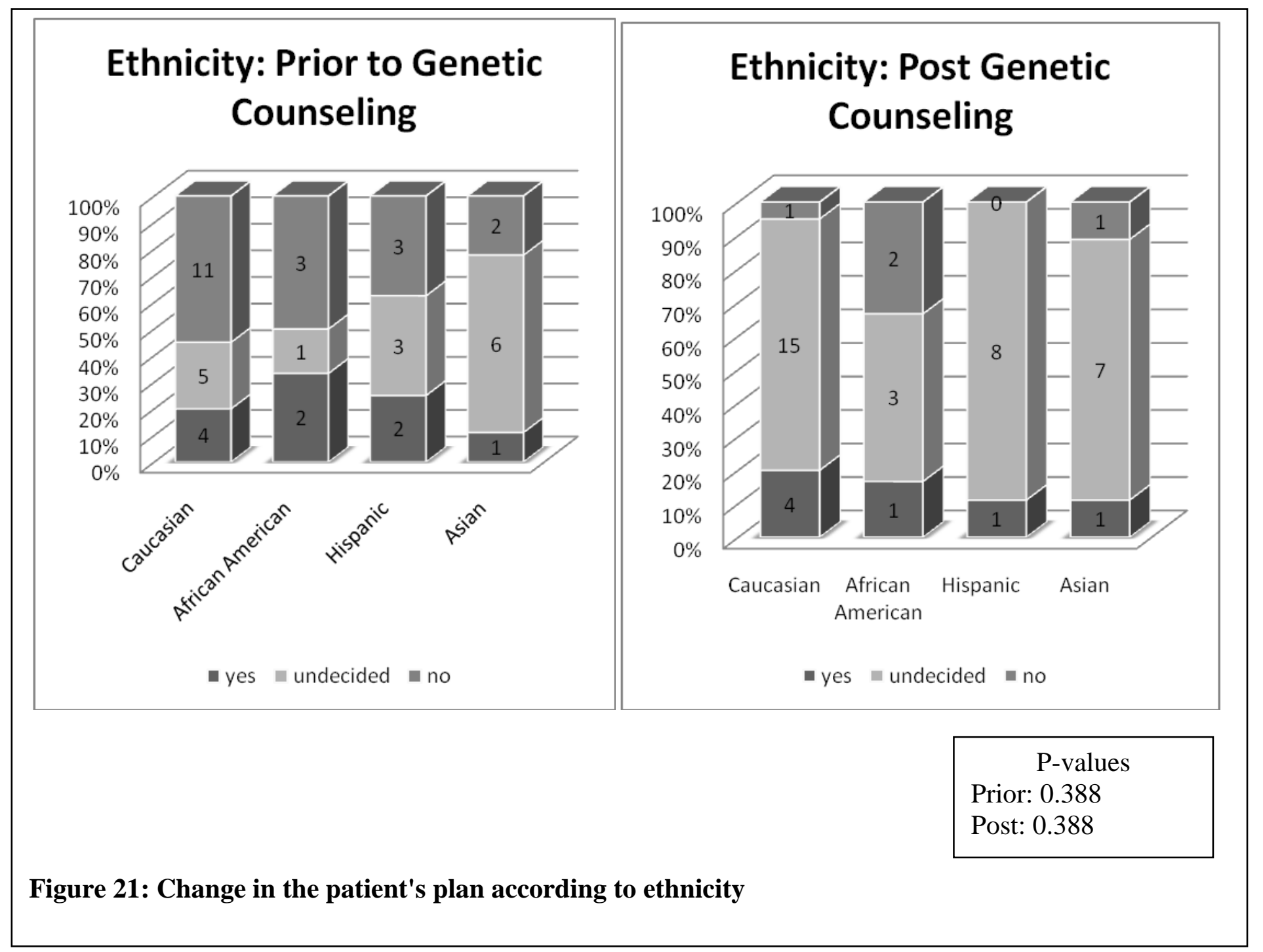


While overall trends were not found, we were able to determine that many of our participants changed their original plan regarding PDT. For those that did change their original plan, the participants were more inclined to decide to have PDT or were now undecided about having PDT. Age was not an influential factor, as many participants regardless of their age either $<38$ or $\geq 38$ years old changed their plan regarding PDT $(<38$ $(p=.002)$ and $\geq 38(p=.045))$. Other characteristics were however significantly associated with changes in plan regarding PDT to either "yes", "no", or "undecided". Those who had two $(p=0.008)$ and three plus pregnancies $(p=0.004)$; those who went to college $(p=.003)$ and graduate school ( $\mathrm{p}=.046)$; those whose annual household income was $\$ 50,001$ $100,000(\mathrm{p}=.015)$ and those who made $>\$ 100,000(\mathrm{p}=.008)$; those from a Caucasian background $(\mathrm{p}=.002)$; those who had one living child $(\mathrm{p}=.001)$ all were significantly more likely to change their initial plan regarding PDT after completing their genetic counseling session. 


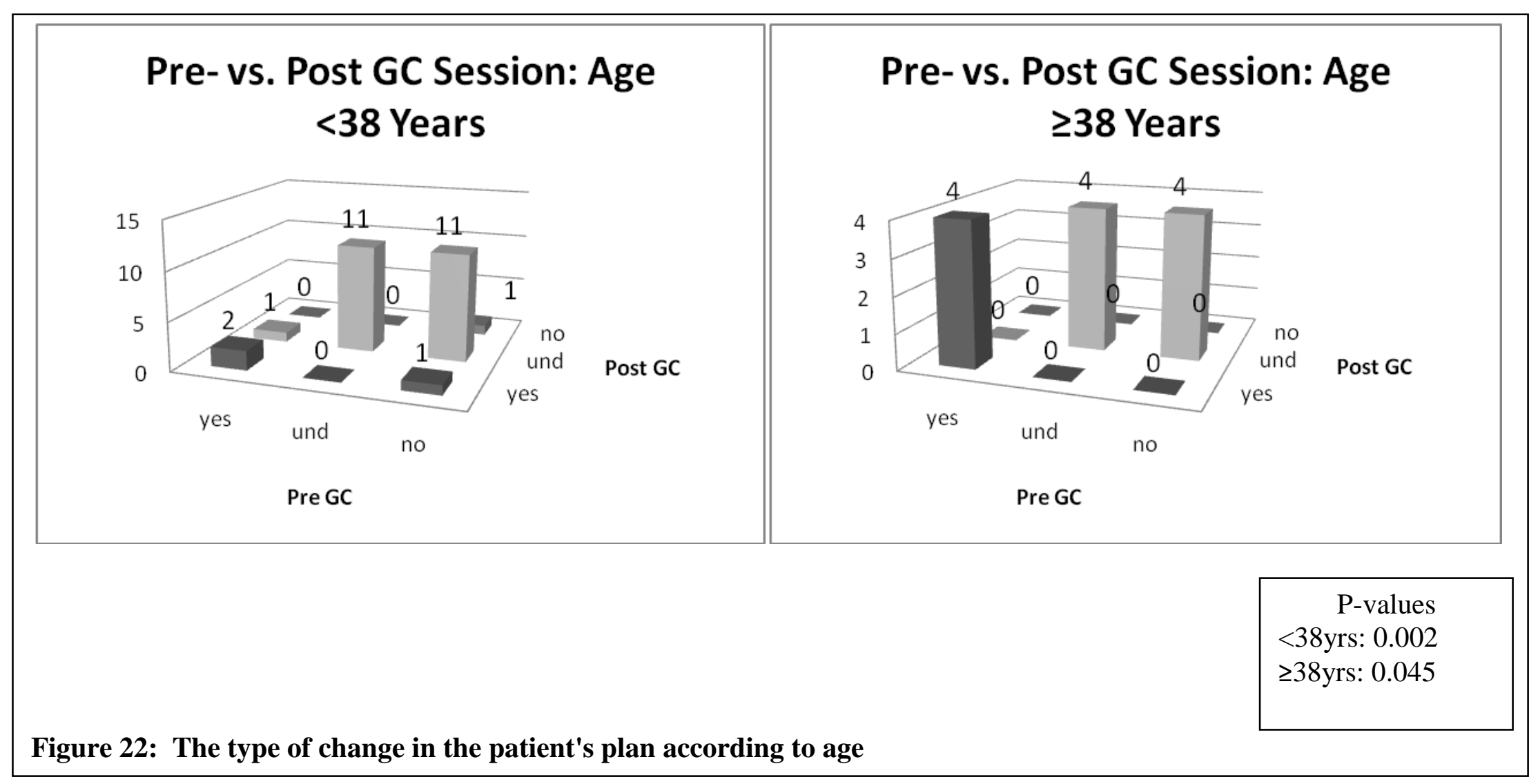




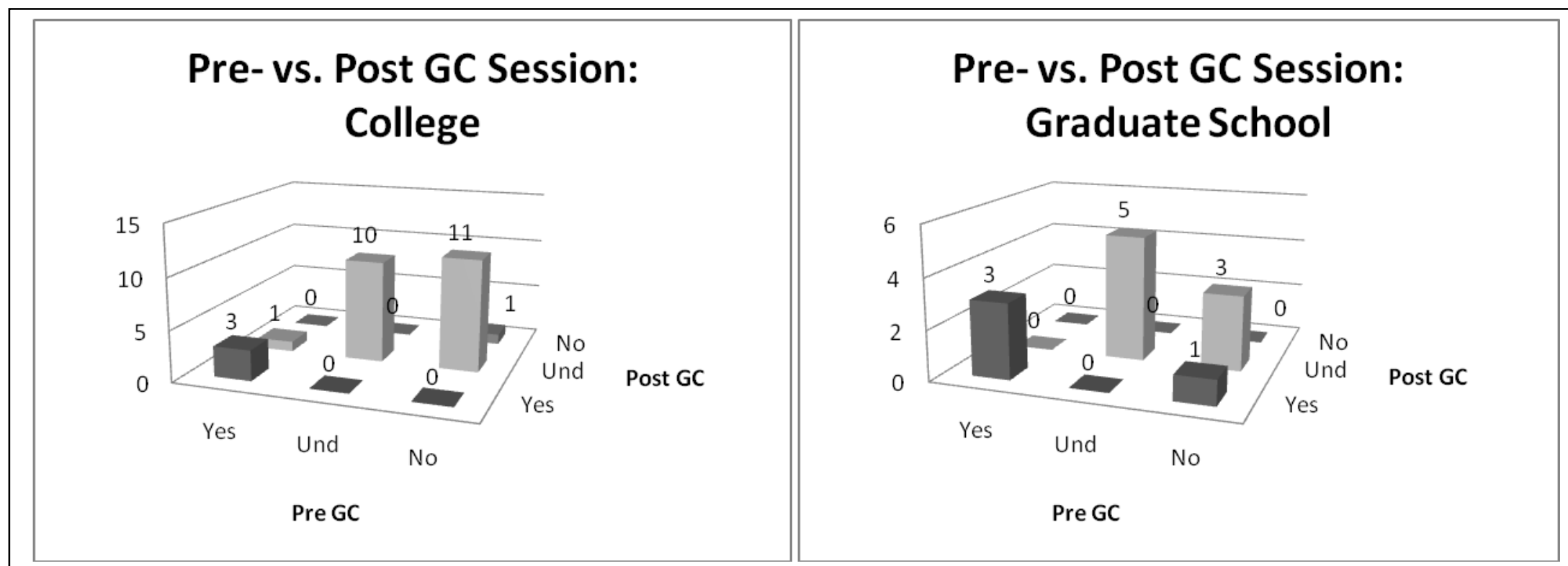

P-values

College: 0.003

Grad School: 0.046

Figure 23: The type of change in the patient's plan according to education 


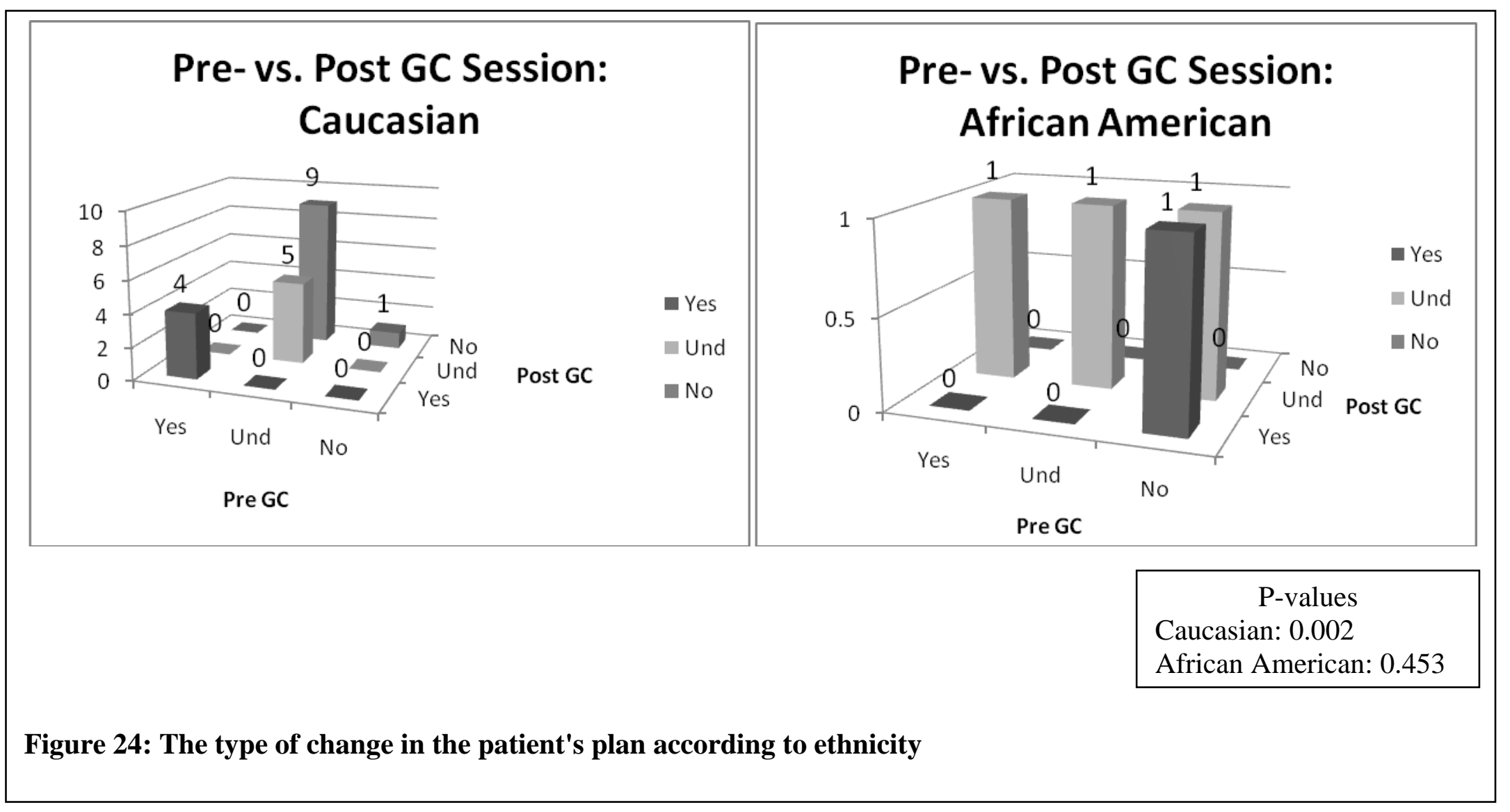




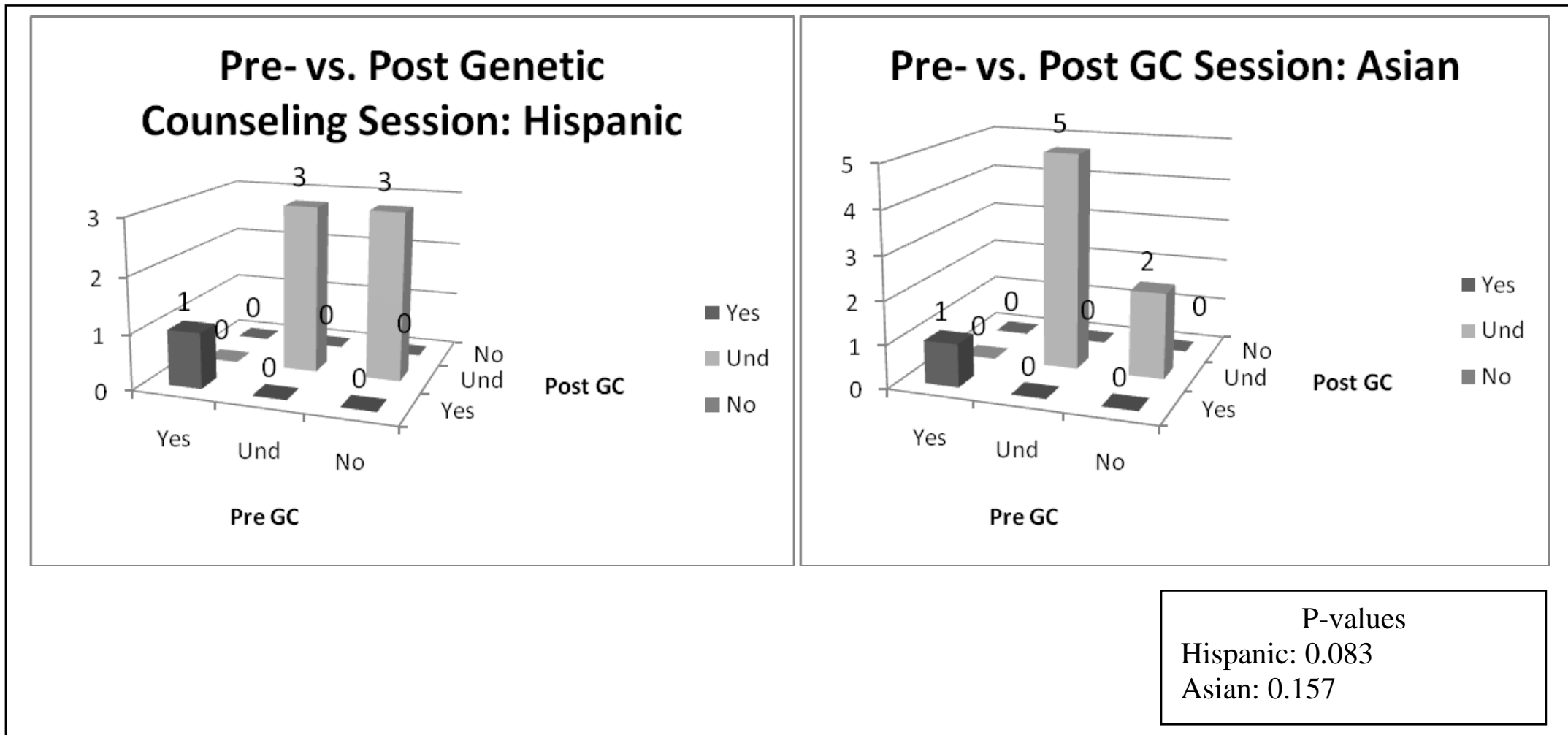

Figure 25: The type of change in the patient's plan according to ethnicity 


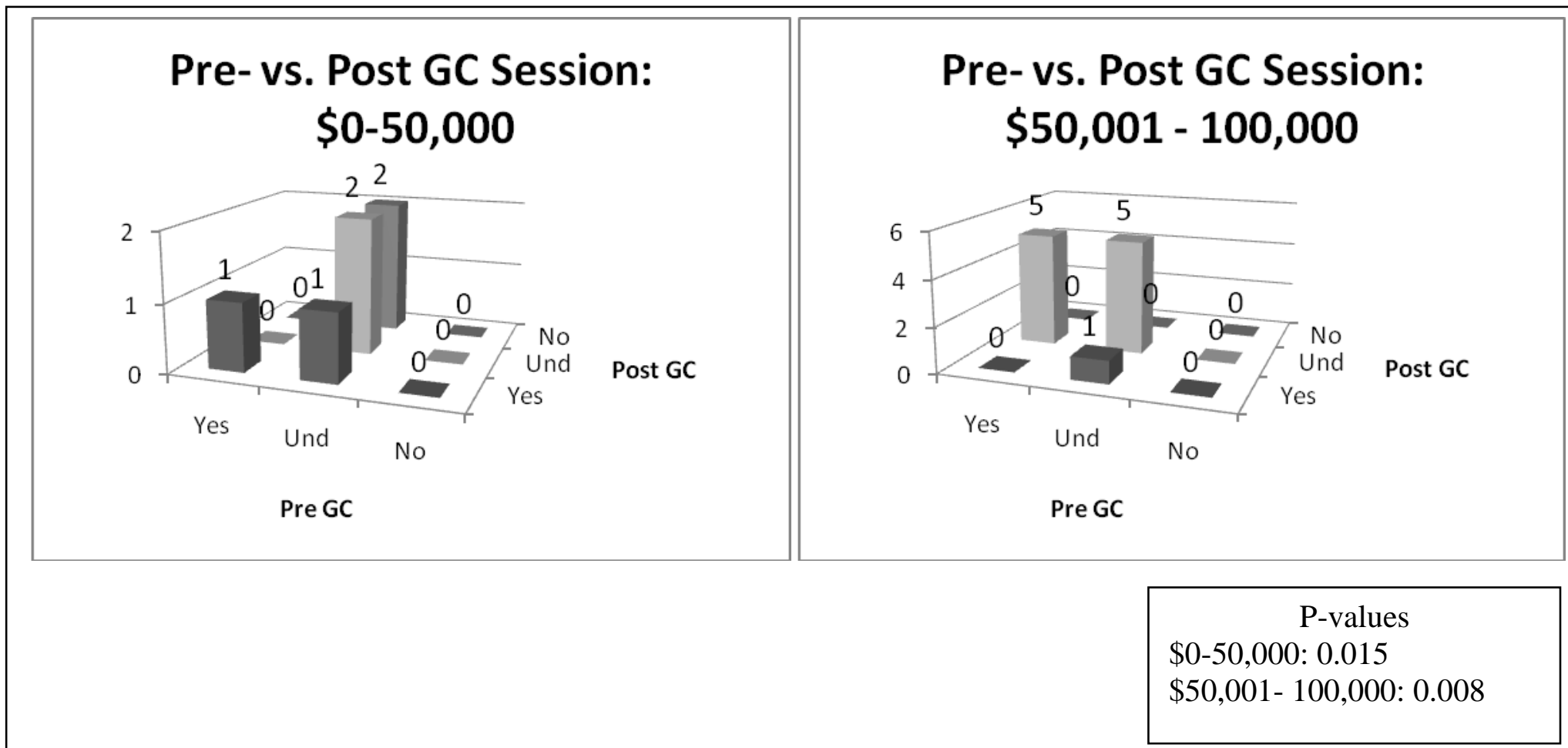

Figure 26: The type of change in the patient's plan according to income 

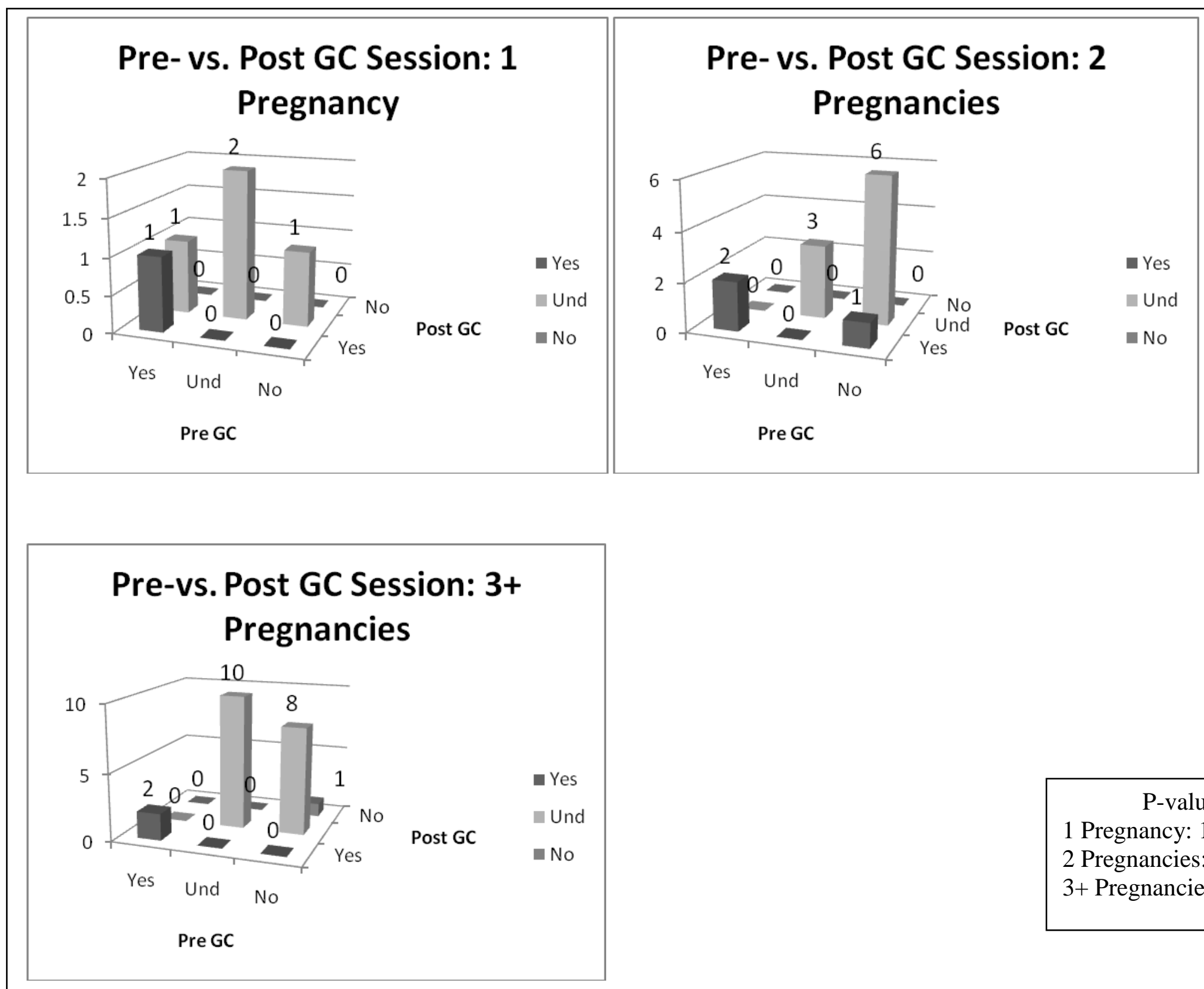


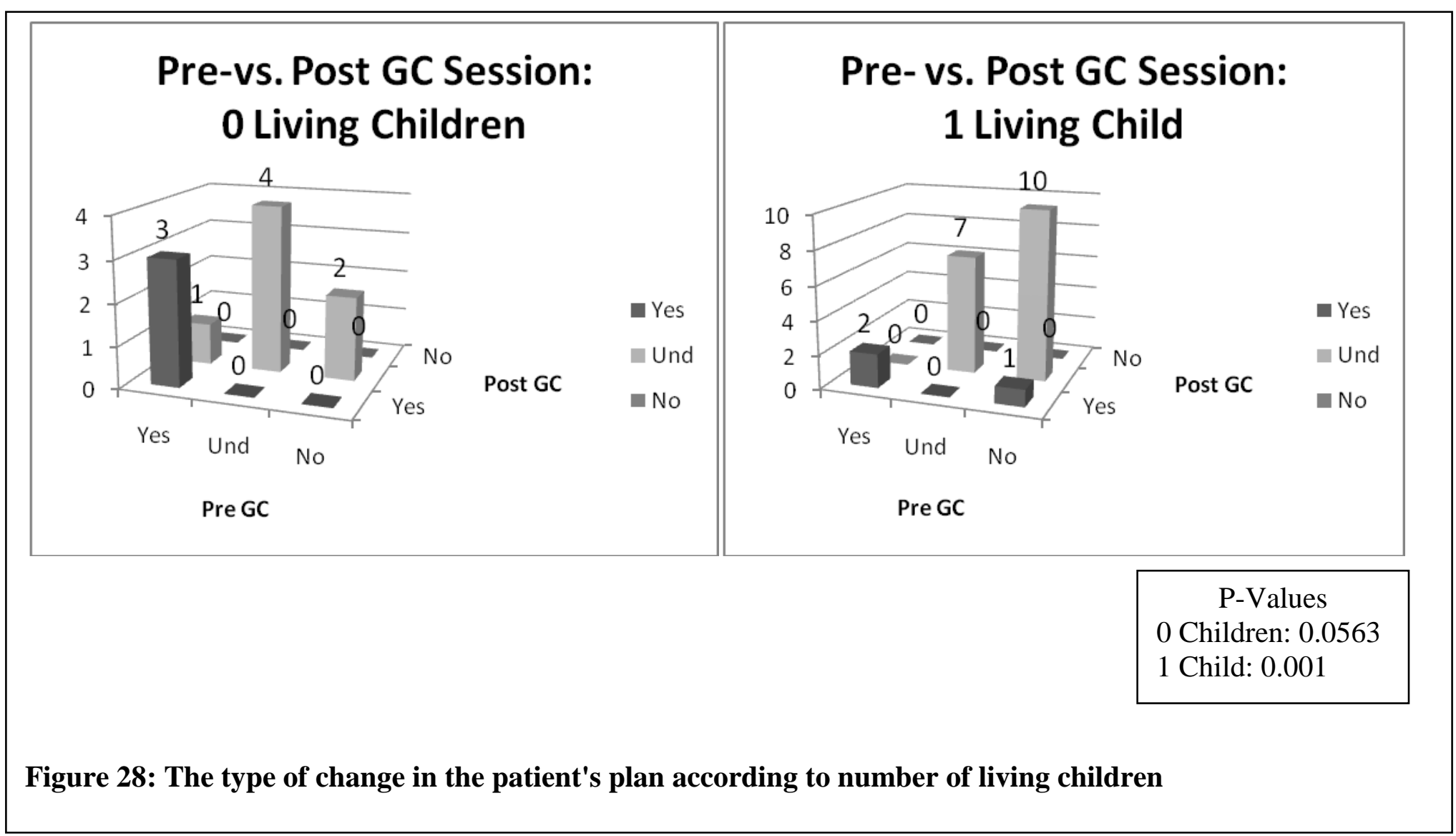




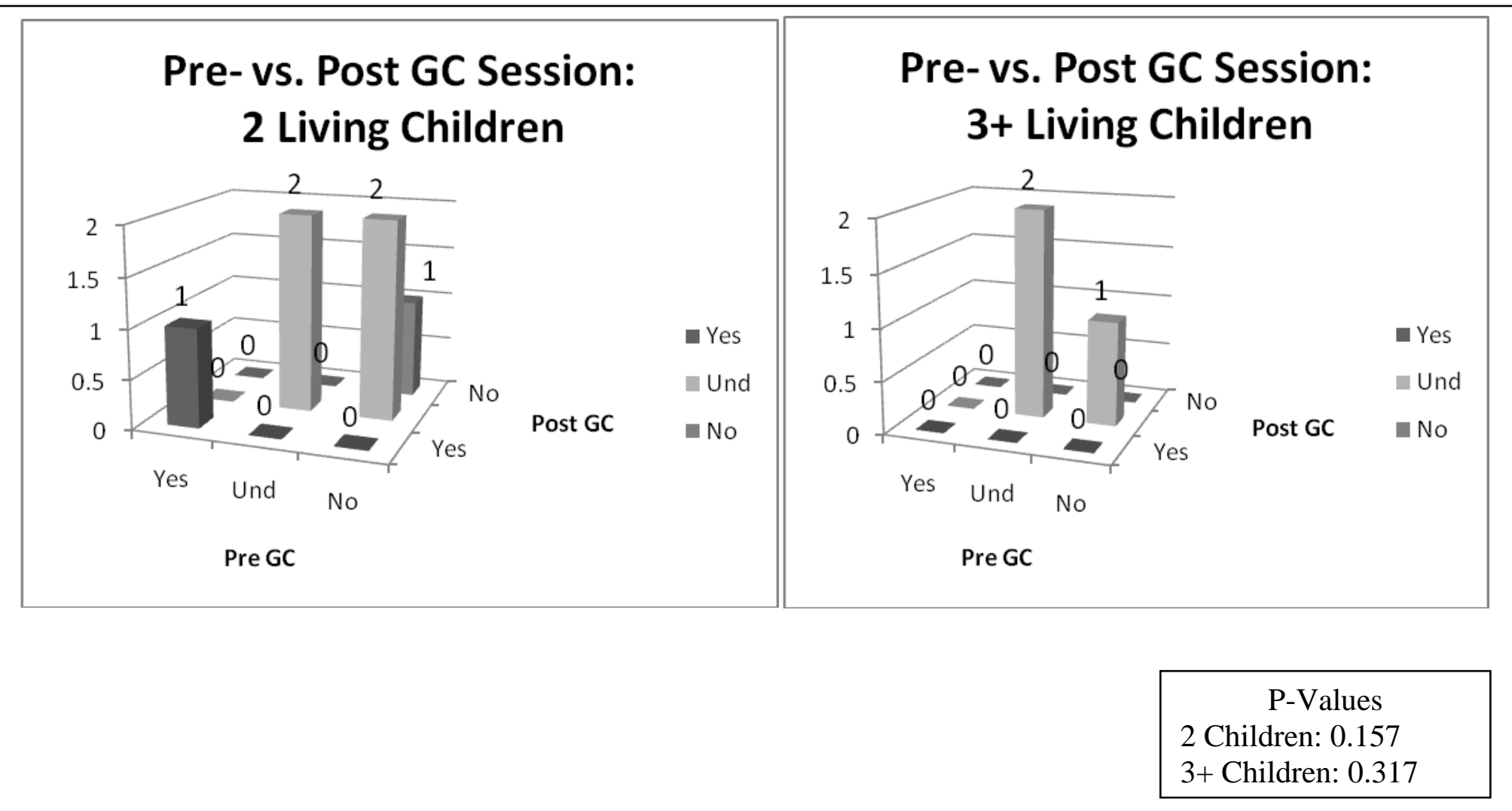

Figure 29: The type of change in the patient's plan according to number of living children 


\section{$\underline{\text { Discussion }}$}

Each year the number of women who have children at or after the age of 35 years increases (NSVR, 2009). With more women in the AMA category, more women are seen at our clinics for genetic counseling with options for ultrasound, screening tests, and/or diagnostic testing. With this increase, one could hypothesize that there should also be an increase in the amount of PDT procedures performed. However, this does not appear to be the case. Many studies have suggested that there has been a decline in the amount of PDT procedures and that this decline may be attributed to the availability of nuchal translucency screening (Mulvey and Wallace 2000; Dommergueset al. 2001; Zoppi et al. 2001; Chasen et al. 2004). While most of these studies evaluated women who only had nuchal translucency screening, one study evaluated women who had FTS (nuchal translucency plus analytes) (Wray et al. 2005). Wray et al. determined that women used FTS as a way to help them decide whether or not to have PDT. They also determined that their patients were comfortable with the accuracy of FTS and preferred to have this option available to them rather than to only be offered PDT (Wray et al, 2005). While the previously mentioned studies determined a decrease in PDT uptake, there have been no studies, to our knowledge, which examined both patient knowledge of FTS and their intentions towards PDT with regard to FTS.

This study sought to determine if there was a change in the uptake of PDT and if that change coincided with release of the January 2007 ACOG statement. The specific aims of this study were to determine 1) if there has been a change in the uptake of PDT following the January 2007 ACOG statement, 2) whether or not FTS results affect patients' choice to 
proceed with or decline PDT, and 3) the patients' intentions regarding PDT both before and after FTS information was given to them during their genetic counseling session.

We hypothesized that there has been a statistically significant decrease in the uptake of PDT in our clinics following the January 2007 ACOG statement and that we it would be able to identify factors which were influential to the patient during their decision making process regarding PDT.

This study concluded that while there was an increase in the number of AMA women seen in our clinics, there was a decrease in the number of PDT procedures performed. We determined that most patients either did not want PDT or were undecided about PDT prior to their genetic counseling session, but the vast majority became undecided about PDT after their session.

\section{Surveys}

The majority of our study population included women who were highly educated, were from a Caucasian ethnic background, and had a higher than average annual household income. These demographics are indicative of the type of patients who are primarily seen for genetic counseling for AMA in the first trimester at our clinics and who elected to complete our surveys. This suggests that those who are interested in FTS, or are informed about FTS, are those who may be financially able to seek early prenatal care and obtain this screening. It may also be indicative of women who are planning their pregnancies and therefore are aware of their pregnancies early enough to obtain FTS.

Our participants were largely aware of the basics of FTS. The majority of participants stated that they learned about FTS from their OB/GYN, which was supported by 
our referring physician respondents who stated they are the primary person who explains FTS to their patients. For a genetic counselor who seeks to educate patients regarding the benefits and limitations of all testing options, how patients are initially informed about FTS is of significant interest. A small portion of our patient participants (18\%) believed that FTS could in fact be done instead of PDT. This percentage is close to that of referring physicians (17\%) who stated that they advised their patients that FTS could be done instead of PDT. We did not ask our participants if they believed FTS would give them the exact same information as PDT, therefore we cannot accurately assess if the participants believed FTS was a comparable replacement for PDT or if it was just a preferred alternative to PDT. Prior to their genetic counseling session, over half (53\%) of our patient participants believed that FTS could be used to determine if their baby would have a birth defect. This is a common and understandable belief as many people may consider trisomy 21 a birth defect. Although we thought that this belief would be resolved after the genetic counseling session, the post-counseling survey indicated that $38 \%$ of our participants still felt that FTS could be used to determine if their baby would have a birth defect. Though patients are educated about fetal aneuploidy and its origins, it is possible that a patient may still view these anomalies as birth defects. Another explanation could be the fact that many of our counselors discuss the fact that an increased nuchal translucency may indicate a cardiac defect and/or other birth defects/genetic conditions. Careful consideration for the way genetic counselors explain the differences between birth defects, chromosomal anomalies, and what anomalies FTS can detect may be advisable because of this apparent confusion.

Many factors may play a role in the decision making process when the patient decides to have FTS. One factor we considered was the timing of the screening test. Fifty- 
seven percent of our respondents stated that they wanted to have FTS because it would give them information early in the pregnancy. While there are many reasons why a woman would seek out an early screening option, one reason could be the desire to obtain information about possible fetal abnormalities as soon as possible. One could infer that given the increased risk that mothers who are AMA have for fetal aneuploidy, women could be seeking early prenatal care as a way to diminish the level of anxiety they may be feeling due to this increased risk. While FTS would not be able to give women a definitive answer regarding fetal aneuploidy, it would be able to give them a more personal risk assessment which could mitigate some of their stress. The second ranked factor was that FTS would help them determine if they want to have an amniocentesis or CVS. Thirty-five percent of our referring physician respondents stated that they advised their patients that FTS would help them with their decision to have PDT and 22\% felt FTS was essential to that decision making process. Therefore, patients may already have the outlook that FTS will aid them in their decision making process regarding PDT prior to attending their genetic counseling appointment. The third highest ranked response, which stated that patients wanted to prepare themselves for the possibility of having a child with a chromosome abnormality, was also expected to be in the top ranked answers. While many would not want to take the risk associated with PDT, they still would like to get information in a non-invasive manner to help them mentally prepare for the possibility.

An important aspect of prenatal genetic counseling is educating patients not only about the risk for fetal aneuploidy, but also about the various options a patient has for evaluating this risk (Berkowitz, Roberts et al. 2006). As expected, once a patient has more detailed information about a screening or procedure, she is able to make a more educated 
decision. We asked our participants if their plan to have PDT changed after their genetic counseling session. While there was not a statistically significant change, most likely due to our small sample size, our findings suggest that there is a trend for patients to become undecided about the option of PDT. Seventy-six percent of our respondents on the postcounseling survey stated that they were undecided and that they would use their FTS results to help make this decision. This represents an increase from the $29.8 \%$ who initially stated they were undecided about PDT on the pre-counseling survey. This change demonstrates that many patients may not be receiving enough information about both FTS and PDT prior to genetic counseling and therefore are either misinterpreting the intended usage of FTS or they are making their decision based on inadequate information.

\section{Database Review}

As observed by others, the availability of FTS seems to have changed the number of women who are deciding to undergo PDT. Although FTS was previously offered to our patients, a clinic policy was created following the January 2007 ACOG statement that stated that all women referred for AMA/FTS are to have genetic counseling prior to their screening. We aimed to determine if there has been a significant change in the number of PDT procedures performed and if that change could be attributed to the published guidelines by choosing the two years prior and the two years after the January 2007 ACOG statement.

When comparing 2005-2007 and 2007-2009 periods, we determined that there was an $8.5 \%$ increase in the number of women who received genetic counseling for AMA at all UT associated clinics. At the same time, a $14.8 \%$ decrease in the number of PDT procedures was identified at all of our UT clinics $(\mathrm{p}=<0.05)$. There could be many reasons 
for the increase in the number of AMA patients we are now providing care for. These factors could range from patients receiving recommendations from friends or family, more referrals from physicians, and/or a growing number of AMA women in the general population. During the span of our study we did not inquire about the reason why more patients were seeking genetic counseling. Though we did not take steps to measure all possible factors, one possible reason for the increase is suspected to be the increased awareness and opportunity to obtain FTS at our facility, as well as the January 2007 ACOG statement. Though most patients we surveyed reported that the ability to obtain information early in their pregnancy was their primary reason to have FTS, 7 (13\%) stated they were pursuing FTS due to the fact that it did not pose a risk to their pregnancy. This response was also the fourth ranked reason why women were pursuing FTS. This demonstrates that many women may be choosing FTS because they do not want to take the risk of miscarriage which is associated with PDT. While this response is only representative of those who participated in our study, it does shed light on the fact that many women may accept FTS simply because of its innocuous nature even though the results of FTS cannot replace those from PDT.

In addition to comparing the rates of PDT in the 2005-2007 to the 2007-2009 time periods for our three specified clinics (Figures $5 \&$ 6), we also compared the rates of PDT during our survey collection time frame to that of the 2007-2009 time period. Our comparison between the 2007-2009 time period and our study time period yielded a significant $\mathrm{p}$-value $(\mathrm{p}=0.031)$. This signifies that these two populations of patients are different. Within our clinics there was already an observed decrease in the amount of PDT performed. Therefore comparing these two groups would expectedly yield a significant $\mathrm{p}$ value since we are comparing a time when PDT procedures were diminishing to a time when 
PDT procedures are at an all time low. It is important to note however, that we only determined the number of women who had PDT within our survey distribution period. There are women who participated in the last month of our survey distribution who were not yet eligible for amniocentesis and therefore may not have made their decision yet regarding PDT. In addition, there may be women who participated in the last 3 months of our survey who are still in their second trimester and eligible for amniocentesis. This means that these women may still choose to have PDT, but may not have had the opportunity to do so prior to the completion of this study, and therefore are not counted in the "elected to have PDT category”.

Since $82 \%$ of our patient participants stated that they would use their FTS results to make their decision of whether or not to have PDT, we evaluated the FTS database for our study period to determine the number of women who had FTS, what type of result (positive or negative) they had, and if they had PDT. This group of women included those who did and did not participate in the survey portion of our study. Though there were six times as many negative results as there were positive results, there were three individuals from each category who accepted PDT. Of note, it is possible that those women who had FTS towards the end of our study period may still be in an appropriate time frame to pursue PDT and therefore would not be taken into consideration. Therefore, the exact number of positive and negative results and the number of women who had PDT could differ from our current numbers. Notwithstanding this possibility, our results do show that women are using their FTS results to aid them in their decision to have PDT. If the results of the FTS were not influential we would expect to see more individuals accepting PDT from the screen negative category. 
Although there was a decrease in the number of PDT performed in the 2007 to 2009 time period when compared to the $2005-2007$ time period, $35 \%$ of the population obtained PDT. Although we anticipated that many of these patients sought care at our clinics in the second trimester, we wanted to determine how many patients, if any, were seen in the first trimester and received FTS. During the 2007-2009 period there were 25 (3.3\%) women who had PDT and also had FTS (NT alone or NT+ analytes). Of those women, there were eleven positive results, eight negative results, and six incomplete FTS (NT measurements alone). During our study period there were ten (10.3\%) women who had PDT and also had FTS (NT or NT + analytes). Among them there were three positive results, five negative results, and two incomplete FTS (NT measurements alone). With this particular subset of women it appears that the type of result did not influence whether or not they went on to have PDT. While it is not unusual for women to have FTS and then decide to have PDT, it is interesting that all of these women, regardless of their result, elected to have PDT. We did not evaluate the database for the 1,370 women who did not pursue PDT, therefore, we do not know if they initially had FTS or sought a screening option in the first trimester. Therefore, an accurate assessment of whether or not patients in this time period are actually using their FTS results to assist them in their decision to pursue PDT cannot be made at this time. 


\section{Confounding Factors}

Although our population was largely homogenous, we sought to determine if there were any confounding factors which may have influenced the patient's decision to have PDT. All of our chi-squared analyses were non-significant when we compared each of our possible confounding factors to the pre- and post-counseling patient survey question regarding their plan towards PDT. Though we did not see an overall significant trend, we evaluated each possible confounding factor by Wilcoxon rank test. The age of our participants did not seem to influence their decision regarding PDT. Education and income also did not appear to be an influential factor, since the majority of our participants were highly educated (college and graduate school) or had an above average annual household income $(\$ 50,001-100,000$ and $>\$ 100,000)$. We did find that those who where Caucasian and had one child were likely to say "yes" or become "undecided" about PDT. While these two groups were significant, they were also representative of the majority of the women who participated in this study. Therefore, we cannot specifically say that having a Caucasian ethnicity and having one child are confounding factors in the patient's intentions towards PDT.

One factor that may be influential is the genetic counseling session itself. We did not specifically ask any questions regarding how patients viewed genetic counseling and how it affected their decision to accept FTS and/or PDT. However, we observed a trend of our participants becoming "undecided" about PDT. This was especially noticeable for those women who initially would have not pursued PDT, but became undecided afterwards. Therefore, genetic counseling itself and the detailed information given to patients during the session may be a confounding factor. 


\section{$\underline{\text { Study Limitations }}$}

The prenatal database is maintained by each individual genetic counselor. Therefore issues such as name misspellings, boxes not selected, data incorrectly input into the database, missing patients, or corruption of the dataset may occur. Although such errors would be expected to occur randomly, any of those errors could influence the results of this study. Another possible limitation is the fact that some patients may have PDT at a different facility. Therefore, updated information on the patient's decision to have PDT may not be accurately accounted for in the database. Furthermore, participants who obtained FTS during the last month of our study period may still be eligible for amniocentesis, and therefore have not yet decided about PDT. This means there could be more women who may actually have PDT that we cannot account for.

A limitation of our patient survey is the fact that it included only those women who voluntarily participated in this study. While we believe our results to be indicative to our patient population at our clinics, we do not believe our results could be applied to other populations. This means that our results are most likely only representative for those women who accepted the referral for genetic counseling and who also elected to complete the pre- and post-counseling survey. They may not necessarily reflect the demographic status, the level of knowledge, and reasoning of all AMA women in the population. Therefore, it is recommended that future studies evaluate other populations to determine the effect FTS has on uptake of diagnostic testing.

There may have been logistic impediments to the participation in the study for some eligible women: late arrival for appointment, language barrier, and other communication problems. Therefore, our results may not accurately reflect the opinions and thoughts of 
those who do not speak English fluently and those who did not show up on time to their appointment. Furthermore, the distribution of the patient survey was largely dependent on the front desk staff. Consequently, eligible patients may not have received the survey or the survey may have been distributed to ineligible patients. While the genetic counselor should have discontinued the survey distribution to ineligible patients, there was not a protocol in place for what the staff or genetic counselor was suppose to do with surveys completed by ineligible patients. Without a protocol in place, it is possible that ineligible patients could be included in this study, which may account for why there were more pre-counseling surveys in comparison to the post-counseling survey.

While the questions included on the questionnaire were reviewed on multiple occasions and simplified, some questions may have been unclear and/or misinterpreted leading to an inaccurate response. Finally, because the surveys were to remain anonymous we were not able to determine what each individual participant decided about PDT and if their intentions accurately reflected their actions.

\section{$\underline{\text { Strengths }}$}

The prenatal database was a major strength of the study. We were able to obtain a large sample size which conferred reasonably reliable results. In addition, by doing both patient and physician surveys, we were able to ascertain the type of information patients are given about FTS and determine what factors affect the patient's early decision regarding

PDT. Also, by having both a pre- and post-counseling survey, we were able to assess how complete information pertaining to FTS can affect the patient's decision and intentions toward PDT. 


\section{Future Studies}

In this study we attempted to determine the change in the uptake of PDT, and also what factors may influence the patients' decision to accept or decline PDT. We were able to determine the reasons why a patient may pursue FTS and if they changed their plan regarding PDT after their genetic counseling session; however, we could not precisely determine if each participant intentions actually reflected their action. The inability to determine this stems from the fact that the surveys were anonymous and we were not able to follow-up with each individual patient later in their pregnancy.

Future studies to accurately determine a patient's decision making process pertaining to PDT should follow a patient from their first trimester throughout their second trimester. By doing this, one would be able to ascertain even more factors a patient considers when making a decision regarding PDT, more accurately ascertain if PDT occurred, and determine if that action accurately reflected the patient's initial statements regarding this matter. Understandably, this process would eliminate the anonymity of intermediate surveys. Considering the possibility that genetic counseling itself may be an influential factor in a patient's decision to have PDT, future studies may want to consider evaluating patient attitudes toward genetic counseling, the level of information they obtained during their session, and how genetic counseling may influence their decisions to have FTS and/or PDT.

In summary, this study was able to determine a significant decrease in the number of PDT procedures performed in our clinics between the time periods 2005-2007 and 20072009. While this change had been observed in various other studies, we also concluded that FTS has greatly influenced this trend. Although our patients admittedly pursued FTS due to its early timing, the information it could provide, and the non-invasive manner of the test, 
many of our patients still considered utilizing PDT after their genetic counseling session. Although our patients preferred to use the FTS results before deciding about PDT, after their genetic counseling session more individuals appeared open to obtaining PDT. Though we did not find any confounding factors, it appears that genetic counseling itself and the information given during the session may influence the patient's decision. 
First Trimester Screening and its Impact on Uptake of Diagnostic Testing

\section{CPHS HSC \#:}

\section{Obstetrician Invitation to Participate:}

You are being asked to take part in a research project called "First Trimester Screening and its Impact on Uptake of Diagnostic Testing" conducted by Deanna Darnes, genetic counseling graduate student, and Jennifer Czerwinski, genetic counselor. Your decision to take part is voluntary and you may refuse to take part or choose to stop taking part at any time. You will be asked questions pertaining to First Trimester Screening and how you present information about this screening option to your patients. You may refuse to answer any questions asked or written on the survey. The research study has been reviewed by the Committee for the Protection of Human Subjects of the University of Texas Houston Health Center.

If you agree to participate in this study, please complete the survey attached to this form. Description of Research:

This study is looking to discover if there has been a meaningful change in the number of women who decide to have an amniocentesis or chorionic villus sampling over the past 4 years and if this change occurred at the same time that First Trimester Screening became standard of care. This study will also survey patients to learn the way women use their First Trimester Screen results in regards to accepting or declining amniocentesis or chorionic villus sampling as a part of their prenatal care. In addition to surveying patients, we will also survey obstetricians, in an effort to understand what information regarding First Trimester Screening is initially given to patients.

\section{Time commitment:}

It should take you less than 10 minutes to complete this survey.

\section{Benefits:}

The results of this study may help health care professionals better meet the needs of their patients.

\section{Risks:}

There are no known risks to you from your participation in this study.

\section{Confidentiality:}

You will not be personally identified in any reports or publications that may result from this study.

\section{In case of injury:}

If you suffer an injury as a result of taking part in this research study, please understand that nothing has been arranged to provide free treatment of the injury or any other type of payment. However, all needed facilities, emergency treatment and professional services, will be available to you. You should report any injury to Deanna Darnes, 505-604-3683 and to the Committee for the Protection of Human Subjects, (713) 500-7943.

\section{After reading this information form and you would like to participate in this study please complete the survey on the next page. CPHS STATEMENT:}


This study (HSC-______ ) has been reviewed by the Committee for the Protection of Human Subjects (CPHS) of the University of Texas Health Science Center at Houston. For any questions about research subject's rights, or to report a research-related injury, call the CPHS at (713) 5007943. 


\section{Instructions}

\section{Referring Physician Survey}

\section{ability.}

Please read each question carefully and answer each question to the best of your

1. Who do you refer for First Trimester Screening? (circle all that apply)

a) All of my patients

b) Only women who are of Advanced Maternal Age ( $\geq 35$ at delivery)

c) Only women under 35 years of age

d) Only women who would consider termination if their fetus was affected with a chromosomal abnormality, i.e. Trisomy 21 or Trisomy 18

e) Only women who have had prior pregnancies that were affected with a chromosomal abnormality

f) Other:

2. How do you routinely present the option of First Trimester Screening to your patients? (circle all that apply)

a) I tell them that it can be done instead of doing an Amniocentesis and Chorionic Villus Sampling (CVS)

b) I tell them it will help them make their decision about whether or not to have an Amniocentesis or Chorionic Villus Sampling (CVS)

c) I tell them that it will give them information about their risk for having a child with chromosomal abnormalities such as Trisomy 21(Down syndrome) or Trisomy 18

d) I give them a brochure to read

e) Other:

3. Who routinely talks to your patients about First Trimester Screening? (circle all that apply)

a) I do

b) A nurse

c) Other:

4. Do you think most of your patients know what First Trimester Screening is prior to you discussing it with them? (circle one)
a) Yes
b) No
c) Other:

5. From what your patients tell you about their experience, how do they generally feel about First Trimester Screening? (circle all that apply)

a) They feel that it is helpful to them

b) They feel that having First Trimester Screening was essential to their decision making process

c) They feel that having First Trimester Screening did not help them with their decisions

d) They feel like they did not really need to have the screening done

e) They feel that First Trimester Screening caused them more worry or anxiety

f) I have not asked my patients this question

g) Other: 
First Trimester Screening and its Impact on Uptake of Diagnostic Testing

\section{Patient Invitation to Participate:}

\section{CPHS HSC \#:}

You are being asked to take part in a research project called "First Trimester Screening and its Impact on Uptake of Diagnostic Testing" conducted by Deanna Darnes, genetic counseling graduate student, and Jennifer Czerwinski, genetic counselor. Your decision to take part is voluntary and you may refuse to take part or choose to stop taking part at any time. A decision not to take part in or stop being a part of this research study will not change the services that are available to you now. You may refuse to answer any questions asked or written on any of the forms. The research study has been reviewed by the Committee for the Protection of Human Subjects of the University of Texas Houston Health Center.

If you agree to participate in this study, please complete the survey attached to this form. Completion of the survey will not delay your appointment for genetic counseling or ultrasound.

\section{Description of Research:}

This study is looking to discover if there has been a meaningful change in the number of women who decide to have an amniocentesis or chorionic villus sampling over the past 4 years and if this change occurred at the same time that First Trimester Screening became standard of care. This study will also survey patients to learn about the way women use their First Trimester Screen results in regards to accepting or declining amniocentesis or chorionic villus sampling as a part of their prenatal care. In addition to surveying patients, we will also survey obstetricians, in an effort to understand what information regarding First Trimester Screening is initially given to patients.

\section{Cost:}

There are no additional costs to you to participate in this study.

\section{Time commitment:}

It should take you less than 10 minutes to complete the first part of the survey. You will receive a second survey after your genetic counseling appointment. That survey should also take less than 10 minutes to complete.

\section{Benefits:}

There are no known benefits to you from participating in this study. The results of this study may help health care professionals better meet the needs of their patients.

\section{Risks:}

There are no known risks to you from your participation in this study.

\section{Confidentiality:}

You will not be personally identified in any reports or publications that may result from this study. Any personal information about you that is gathered during this study will remain confidential to every extent of the law.

\section{In case of injury:}

If you suffer an injury as a result of taking part in this research study, please understand that nothing has been arranged to provide free treatment of the injury or any other type of payment. However, all needed facilities, emergency treatment and professional services, will be available to you. You should report any injury to Deanna Darnes, (505)-604-3683 and to the Committee for the Protection of Human Subjects, (713) 500-7943. 
After reading this information form and you would like to participate in this study please complete the survey on the next page.

\section{CPHS STATEMENT:}

This study (HSC-_______ ) has been reviewed by the Committee for the Protection of Human Subjects (CPHS) of the University of Texas Health Science Center at Houston. For any questions about research subject's rights, or to report a research-related injury, call the CPHS at (713) 5007943. 


\section{Instructions}

\section{Pre-Counseling Patient Survey}

Please read each question carefully and answer each question to the best of your ability.

If you have any questions please ask your genetic counselor. your session.

Please hand this survey to your genetic counselor at the beginning of

1. How old are you?

2. How many times have you been pregnant?

3. How many children do you have?

4. Race/Ethnicity: (circle one)

African-American Hispanic Asian Caucasian Other:

5. Education Level: (circle one)

Some High school High school Some College College

Some Graduate School Graduate School

Other:

6. Annual Household Income: (circle one)

$\begin{array}{lll}\$ 0-25,000 & \$ 25,001-50,000 & \$ 50,001-75,000 \\ \$ 75,001-100,000 & >\$ 100,001 & \end{array}$

7. Religious Affiliation: (circle one)

Christianity Judaism Islam Atheism Hinduism Buddhism

Other:

8. Have you ever had a child with a birth defect or genetic syndrome? (circle one) Yes / No

$$
\begin{aligned}
& \checkmark \quad \text { If yes, please } \\
& \text { specify: }
\end{aligned}
$$

9. Do you or any of your relatives have a genetic syndrome? (circle one) Yes / No

$\checkmark \quad$ If yes, please

specify:

10. Have you ever had an Amniocentesis or Chorionic Villus Sampling (CVS)? (circle one) Yes / No

$\checkmark \quad$ If yes, please specify: (circle one) Amniocentesis / Chorionic Villus Sampling (CVS) / Both

$\checkmark \quad$ If yes, did you have a complication or miscarriage after the procedure(s)? (circle one)

$$
\text { Yes / No }
$$

$\checkmark \quad$ If yes, did you have a (circle one) Complication / Miscarriage 
If you had a complication, what type of complication did you have? (circle all that apply)

Bleeding /Spotting Leakage of Fluid Severe Cramping

Infection

Other:

11. If this is not your first pregnancy, did you have First Trimester Screening during any of your previous pregnancies? (circle one)
a) $\mathrm{No}$
b) Yes
c) Unsure
d) I have not heard of First Trimester Screening

12. So far, who has discussed First Trimester Screening with you? (circle all that apply)
a) No one
b) $\mathrm{OB} / \mathrm{GYN}$
c) General Practitioner
d) Nurse
e) Family/Friends
f) Other:

13. Prior to hearing about First Trimester Screening, were you planning to have an Amniocentesis or Chorionic Villus Sampling (CVS)? (circle one)
a) I have not heard of First Trimester Screening
b) Yes
c) No
d) Undecided
e) I have not heard of an Amniocentesis or Chorionic Villus Sampling (CVS)
f) Other:

14. What is your understanding about what First Trimester Screening can tell you? (circle all that apply)

a) It can be done instead of doing an Amniocentesis or Chorionic Villus Sampling (CVS) and it will tell me the same information about my pregnancy

b) It can tell me my chance to have a baby with a birth defect

c) It can tell me tell me if the baby is at risk for a specific type of chromosome problem

d) It can tell me if the baby is healthy

e) I have not heard of First Trimester Screening

f) Other:

\section{Instructions}

\section{Post-counseling Patient Survey}




\section{Please read each question carefully and answer each question to the best of your ability.}

1. Prior to your genetic counseling session, did you know that you were at an increased risk to have a child with a chromosomal abnormality due to your age alone? (circle one)

a) Yes

b) No

2. During my genetic counseling session, I learned that First Trimester Screening would ? (circle all that apply)

a) Tell me the risk for my baby to have Trisomy 21 (Down syndrome) or Trisomy 18

b) Tell me if anything could possibly be wrong with my baby

c) Tell me the risk that my baby has a birth defect

d) I do not know what First Trimester Screening will be able to tell me

e) Other:

3. I am having First Trimester Screening because ? (rank the following in order

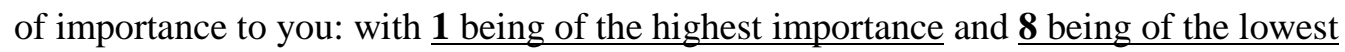
importance)

_A_ I want to obtain information early in the pregnancy about the risk for specific chromosomal abnormalities, like Trisomy 21 (Down syndrome)

_B_ _ It will help me to determine if I want to have an Amniocentesis or Chorionic Villus Sampling (CVS)

_C_ I want to be prepared for the possibility of a baby with a chromosomal abnormality like Trisomy 21 (Down syndrome)

_D_ I would terminate the pregnancy if the baby was at an increased risk for a chromosomal abnormality like Trisomy 21 (Down syndrome)

_E_ It is an easy test to do

_F___ It does not pose a risk to my pregnancy

_G_ My doctor told me that I needed to have First Trimester Screening

_H_ Other: 
4. Are you going to have an Amniocentesis or Chorionic Villus Sampling (CVS)? (circle all that apply)

a) Yes, no matter what my First Trimester Screening results say, I will have an Amniocentesis or Chorionic Villus Sampling (CVS)

b) No, under no circumstances will I have an Amniocentesis or Chorionic Villus Sampling (CVS)

c) I will use the results from my First Trimester Screening to decided whether or not I will have an Amniocentesis or Chorionic Villus Sampling (CVS)

d) Yes, only if my insurance will cover it

e) I have not heard of a Chorionic Villus Sampling (CVS) or Amniocentesis

f) Other:

5. Did your plan to have an Amniocentesis or Chorionic Villus Sampling (CVS) change after learning about First Trimester Screening? (circle all that apply)

a) Yes, after learning about First Trimester Screening I no longer want to have an Amniocentesis or Chorionic Villus Sampling (CVS)

b) Yes, after learning about First Trimester Screening I now want to have an Amniocentesis or Chorionic Villus Sampling (CVS)

c) No, after learning about First Trimester Screening I still want to have an Amniocentesis or Chorionic Villus Sampling (CVS), regardless of what my results are

d) No, I still do not want to have an Amniocentesis or Chorionic Villus Sampling (CVS)

e) I did not have a plan regarding Amniocentesis or Chorionic Villus Sampling; I will decide about that after receiving my First Trimester Screening Results

f) Undecided

g) Other:

Thank you for your participation.

Please return survey to the person who brings you back for your ultrasound appointment. 


\section{Works Cited}

Abma JC, Henshaw SK, Mosher WD, Ventura SJ. (2009, October). Estimated Pregnancy

Rates in the United States, 1990-2005: An Update. National Vital Statistics Reports Vol 58(4) , pp. 2010-1120.

ACOG. (2007b, December). Invasive Prenatal Testing for Aneuploidy. ACOG Practice Bulletin No. 88 , pp. 1459-1467.

ACOG. (2007a, Jan). Screening for Fetal Chromosomal Abnormalites. ACOG Practice Bulletin No. 77 , pp. 217-227.

Berkowitz RL, Roberts J, Minkoff H. (2006). Challenging the strategy of maternal agebased prenatal genetic counseling. JAMA, 1446-1448.

Biagiotti R, Cariati E, Brizzi L, Cappelli G, D'Agata A. (1998). Maternal serum screening for trisomy 18 in the first trimester of pregnancy. Prenatal Diagnosis , 907-913.

Borrell, A. (2009). Promises and pitfalls of first trimester sonographic markers in the detection of fetal aneuploidy. Prenatal Diagnosis , 62-68.

Brambati B, Macintosh MC, Teisner B, Maguiness S, Schrimanker K, Lanzani A, Bonacchi I, Tului, Chard T, Grudninskas JG. (1993). Low maternal serum levels of pregnancy associated plasma protein A (PAPP-A) in the first trimester in association with abnormal fetal karyotype. British Journal of Obstetrics and Gynocology, 324-326. 
Breathnach FM, Malone FD, Lambert-Messerlian G, Cuckle HS, Porter TF, Nyberg DA, Comstock CH, Saade GR, Berkowitz RL, Klugman S, Dugoff L, Craigo SD, Timor-Tritsch IE, Carr SR, Wolfe HM, Tripp T, Bianchi DW, D'Alton ME; Evaluati, First and Second Trimester. (2007). First-and second-trimester screening: detection of aneuploidies other than Down syndrome. Obstetrics and Gynecology, 651-657.

Brizot ML, Snijders RJ, Bersinger NA, Kuhn P, Nicolaides KH. (1994). Maternal serum pregnancy-associated plasma protein A and fetal nuchal translucency thickness for the prediction of fetal trisomies in early pregnancy. Obstetrics and Gynocology, 918-922.

Chasen ST, McCullough LB, Chervenak FA. (2004). Is nuchal translucency screening associated with different rates of invasive testing in an older obstetric population? American Journal of Obstetrics and Gynecology, 769-774.

Cicero S, Bindra R, Rembouskos G, Spencer K, Nicolaides KH. (2003). Integrated ultrasound and biochemical screening for trisomy 21 using fetal nuchal translucency, absent fetal nasal bone, free beta-hCG and PAPP-A at 11 to 14 weeks. Prenatal Diagnosis , 306310.

Cicero S, Curcio P, Papageorghiou A, Sonek J, Nicolaides K. (2001). Absence of nasal bone in fetuses with trisomy 21 at 11-14 weeks of gestation: an observational study. Lancet, $1665-1667$. 
Dommergues M, Audibert F, Benattar C, Champagne C, Gomel V, Frydman R. (2001). Is routine amniocentesis for advanced maternal age still indicated. Fetal Diagnosis and Therapy, 372-377.

Dugoff L, Hobbins JC, Malone FD, Porter TF, Luthy D, Comstock CH, Hankins G, Berkowitz RL, Merkatz I, Craigo SD, Timor-Tritsch IE, Carr SR, Wolfe HM, Vidaver J, D'Alton ME. (2004). First-trimester maternal serum PAPP-A and free-beta subunit human chorionic gonadotropin concentrations and nuchal translucency are associated with obstetric complications: a population-based screening study (the FASTER Trial). American Journal of Obstetrics and Gynecology, 1446-1451.

Henry GP, Britt DW, Evans MI. (2008). Screening advances and diagnostic choice: the problem of residual risk. Fetal Diagnosis and Therapy, 308-315.

Hook, E. (1981). Rates of Chromosome Abnormalities at Different Maternal Ages. Obstetrics and Gynecology, 282-285.

Hurley PA, Ward RH, Teisner B, Iles RK, Lucas M, Grudzinskas JG. (1993). Serum PAPPA measurements in first-trimester screening for Down syndrome. Prenatal Diagnosis , 903908. 
Jackson LG, Zachary JM, Fowler SE, Desnick RJ, Golbus MS, Ledbetter DH, Mahoney MJ, Pergament E, Simpson JL, Black S, et al. (1992). A randomized comparison of transcervical and transabdominal chorionic-villus sampling. The U.S. National Institute of Child Health and Human Development Chorionic-Villus Sampling and Amniocentesis Study Group. New England Journal of Medicine, 594-598.

Kagan KO, W. D. (2008c). Screening for trisomies 21, 18 and 13 by maternal age, fetal nuchal translucency, fetal heart rate, free beta-hCG and pregnancy-associated plasma protein-A. Human Reproduction, 1968-1975.

Kagan KO, W. D. (2008b). Screening for trisomy 18 by maternal age, fetal nuchal translucency, free beta-human chorionic gonadotropin and pregnancy-associated plasma protein-A. Ultrasound in Obstetrics and Gynecology , 488-492.

Kagan KO, W. D. (2008a). Screening for trisomy 21 by maternal age, fetal nuchal translucency thickness, free beta-human chorionic gonadotropin and pregnancy-associated plasma protein-A. Ultrasound in Obstetrics and Gynecology, 618-624.

Kirz DS, D. W. (1985). Advanced maternal age: the mature gravida. American Journal of Obstetrics and Gynecology, 7-12.

Ledbetter DH, Z. J. (1992). Cytogenetic results from the U.S. Collaborative Study on CVS. Prenatal Diagnosis, 317-345. 
Malone FD, C. J.-T.-M., \& Secon, F. a. (2005). First-trimester or second-trimester screening, or both, for Down's syndrome. New England Journal of Medicine, 2001-2011. Mulvey S, Wallace EM. (2000). Women's knowledge of and attitudes to first and second trimester screening for Down's syndrome. BJOG : an international journal of obstetrics and gynaecology , 1302-1305.

Nicolaides KH, Azar G, Byrne D, Mansur C, Marks K. (1992). Fetal nuchal translucency: ultrasound screening for chromosomal defects in first trimester of pregnancy. British Medical Journal , 867-869.

Noble PL, Abraha HD, Snijders RJ, Sherwood R, Nicolaides KH. (1995). Screening for fetal trisomy 21 in the first trimester of pregnancy: maternal serum free beta-hCG and fetal nuchal translucency thickness. Ultrasound in Obstetrics and Gynecology, 390-395.

Odibo AO, D. J. (2008). Evaluating the rate and risk factors for fetal loss after chorionic villus sampling. Obstetrics and Gynecology, 813-819.

Odibo AO, G. D. (2008, March). Revisiting the fetal loss rate after second-trimester genetic amniocentesis: a single center's 16-year experience. Obstetrics adn Gynecology, 589-595. 
Orlandi F, Damiani G, Hallahan TW, Krantz DA, Macri JN. (1997). First-trimester screening for fetal aneuploidy: biochemistry and nuchal translucency. Ultrasound in Obstetrics and Gynecology, 381-386.

Spencer K, Ong C, Skentou H, Liao AW, H Nicolaides K. (2000). Screening for trisomy 13 by fetal nuchal translucency and maternal serum free beta-hCG and PAPP-A at 10-14 weeks of gestation. Prenatal Diagnosis , 411-416.

Spencer K, Tul N, Nicolaides KH. (2000). Maternal serum free beta-hCG and PAPP-A in fetal sex chromosome defects in the first trimester. Prenatal Diagnosis , 390-394.

Tul N, Spencer K, Noble P, Chan C, Nicolaides K. (1999). Screening for trisomy 18 by fetal nuchal translucency and maternal serum free beta-hCG and PAPP-A at 10-14 weeks of gestation. Prenatal Diagnosis, 1035-1042.

Werner EF, Pastore LM, Karns LB, Ventura KA, Saller DN. (2008). Patient preferences for screening in the first trimester. Prenatal Diagnosis , 1251-1255.

Wray AM, Ghidini A, Alvis C, Hodor J, Landy HJ, Poggi SH. (2005). The impact of firsttrimester screening on AMA patients' uptake of invasive testing. Prenatal Diagnosis , 350353. 
Zoppi MA, Ibba RM, Putzolu M, Floris M, Monni G. (2001). Nuchal translucency and the acceptance of invasive prenatal chromosomal diagnosis in women aged 35 and older.

Obstetrics and Gynecology, 916-920. 
Vita

Deanna Renee Darnes was born in Blytheville, Arkansas on October $4^{\text {th }} 1984$ the Daughter of Regina A. Darnes. As a part of a military family Deanna moved frequently to various bases around the country, but graduated from Westlake High School in Waldorf, MD in 2003. She graduated from the University of New Mexico, where she received a Bachelor of Science degree in Biology in 2007. In August of 2008 she entered the Genetic Counseling Program at The University of Texas Health Science Center at Houston Graduate School of Biomedical Sciences. 